\title{
Geotechnical Laboratory Testing for 2-D FEM Analysis of Geomorphic and Planar Sloped Caps and Covers for Sustainable Mine Refuse Deposition
}

Sun Hee Park

Follow this and additional works at: https://researchrepository.wvu.edu/etd

Part of the Civil Engineering Commons, and the Environmental Engineering Commons

\section{Recommended Citation \\ Park, Sun Hee, "Geotechnical Laboratory Testing for 2-D FEM Analysis of Geomorphic and Planar Sloped Caps and Covers for Sustainable Mine Refuse Deposition" (2017). Graduate Theses, Dissertations, and Problem Reports. 6375.}

https://researchrepository.wvu.edu/etd/6375

This Thesis is protected by copyright and/or related rights. It has been brought to you by the The Research Repository @ WVU with permission from the rights-holder(s). You are free to use this Thesis in any way that is permitted by the copyright and related rights legislation that applies to your use. For other uses you must obtain permission from the rights-holder(s) directly, unless additional rights are indicated by a Creative Commons license in the record and/ or on the work itself. This Thesis has been accepted for inclusion in WVU Graduate Theses, Dissertations, and Problem Reports collection by an authorized administrator of The Research Repository @ WVU. For more information, please contact researchrepository@mail.wvu.edu. 
Geotechnical Laboratory Testing for 2-D FEM Analysis of Geomorphic and Planar Sloped Caps and Covers for Sustainable Mine Refuse Deposition

\author{
Rogan D. Park
}

Thesis submitted to the

Benjamin M. Statler College of Engineering and Mineral Resources

at West Virginia University

in partial fulfillment of the requirements for the degree of

Master of Science

in

Civil and Environmental Engineering

John D. Quaranta, Ph.D., P.E., Chair

Leslie C. Hopkinson, Ph.D.

Hema J. Siriwardane, Ph.D., P.E.

Department of Civil and Environmental Engineering

Morgantown, West Virginia

2017

KEYWORDS: GLD, geomorphic, conventional planar, isotropic consolidated undrained (ICU), modeling, seepage, infiltration, factor of safety

Copyright 2017 Rogan D. Park 


\section{ABSTRACT \\ Geotechnical Laboratory Testing for 2-D FEM Analysis of Geomorphic and Planar Sloped Caps and Covers for Sustainable Mine Refuse Deposition \\ Rogan D. Park}

This thesis reports the findings of the application of Geomorphic Landform Design principles to the Royal Scot abandoned coarse coal refuse (CCR) pile located in Greenbrier County, West Virginia. The Royal Scot facility has many environmental concerns including severe erosion, acid-mine/rock drainage, and sediment transport. A cap and cover system is proposed to be implemented which incorporates the GLD principles.

A two-layer cap and cover system will be used to reclaim the site and return it back to a stable state and reduce the production of acid-mine drainage. The system is composed of a hydraulic barrier composed of compacted CCR, and a compacted 80\%/20\% mixed growth layer. The 80/20 layer is composed of $80 \% \mathrm{CCR}$ and $20 \% \mathrm{MGro}^{\mathrm{TM}}$ material. The $\mathrm{MGro}^{\mathrm{TM}}$ is a short paper fiber material produced by the WestRock ${ }^{\circledR}$ paper mill in Covington, Virginia. This material provides the characteristics to allow for the growth of grass on the Royal Scot site. A suite of geotechnical laboratory testing was performed including, classification of the coarse coal refuse, compaction, permeability, and strength testing. The results showed that the compacted CCR could perform as a hydraulic barrier to reduce infiltration into the pile, and the strength for slope stability. The permeability of the CCR was in the magnitude of $10^{-6}$ to $10^{-7} \mathrm{~cm} / \mathrm{s}$, and the friction angle for CCR resulted in 25 degrees. The 80/20 growth layer had a permeability of $10^{-4} \mathrm{~cm} / \mathrm{s}$ to allow water for growth, while the friction angle ranged from 10 to 16 degrees.

Finite Element Modeling was performed on a geomorphic and conventional planar slope located on the site to analyze the cap and cover system for slope stability. The analysis consisted of seepage modeling, coupled with slope stability to get a worst-case scenario factor of safety after infiltration from a 100-year storm event had occurred. The geomorphic slope had increased infiltration compared to the conventional planar slope. The geomorphic slope produced higher factors of safety over 2.0, while the conventional planar slope attained factors of safety close to 1.5. 


\section{Table of Contents}

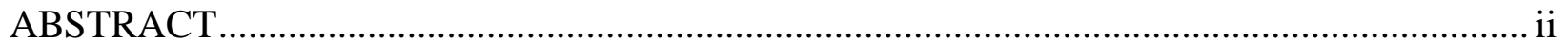

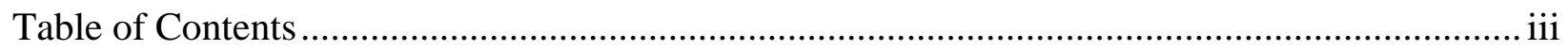

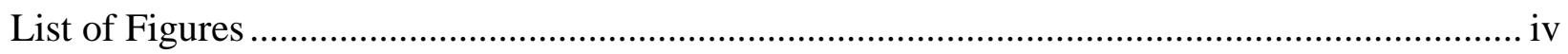

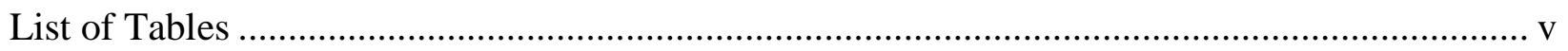

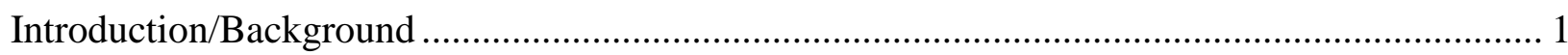

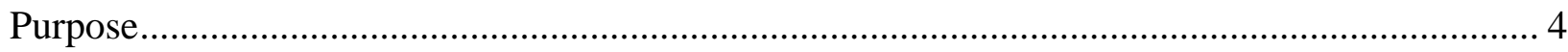

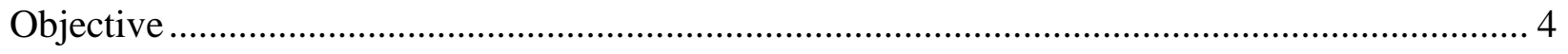

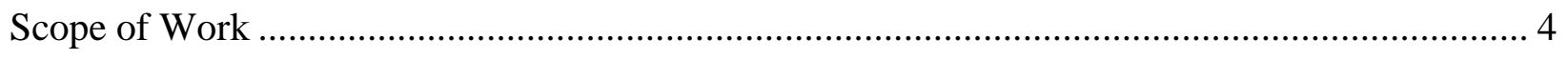

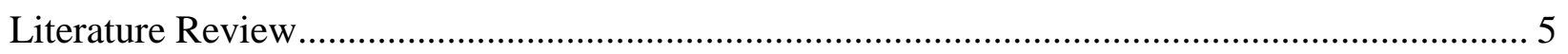

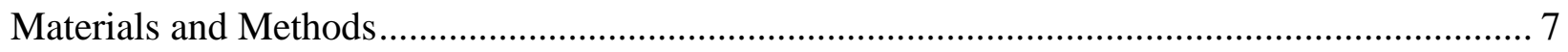

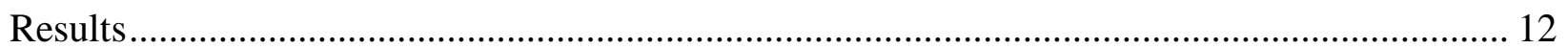

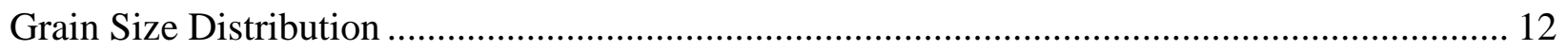

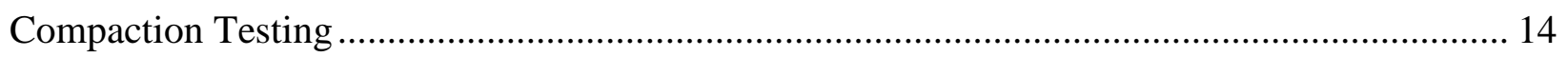

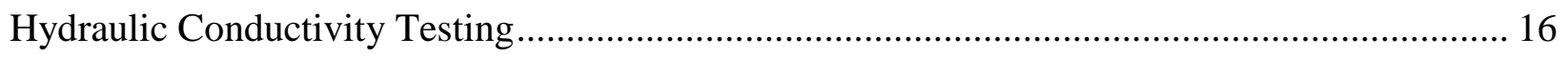

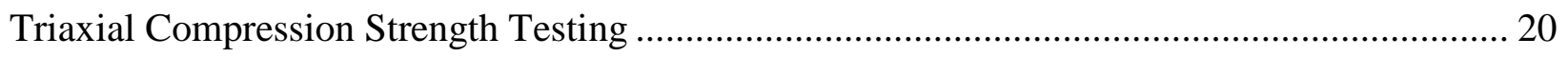

Summary of Geotechnical Laboratory Testing Results .................................................... 28

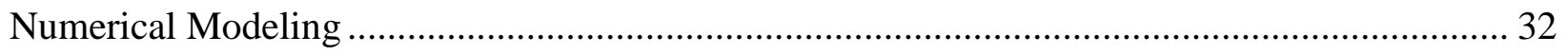

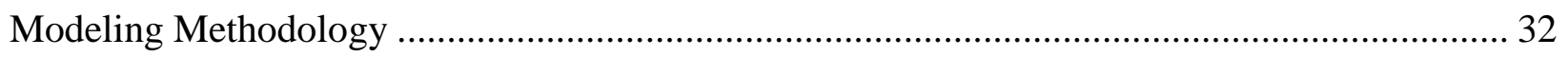

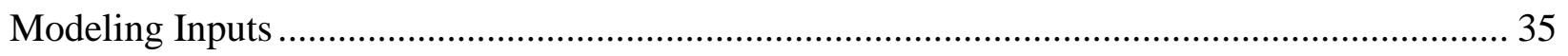

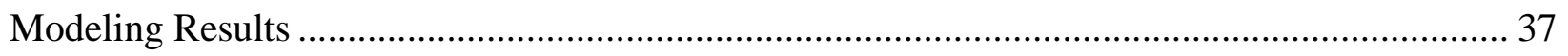

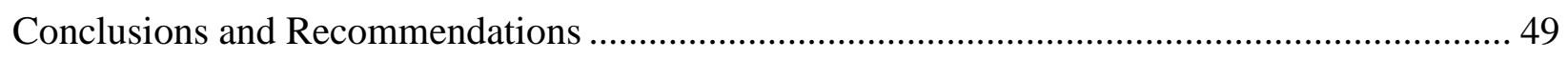

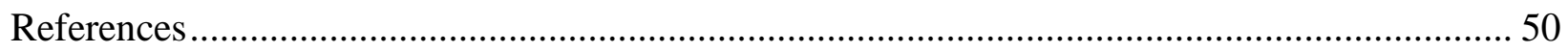




\section{List of Figures}

Figure 1. Location of Royal Scot site and several other coal refuse facilities (Stevens, 2016)..... 1 Figure 2. Cross-section of previous proposed growth layer and hydraulic barrier (Stevens, 2016)2

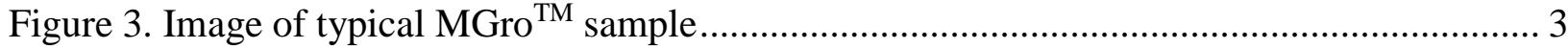

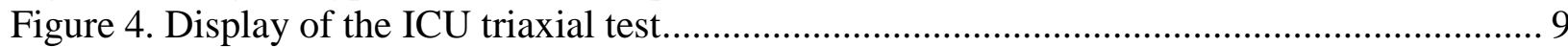

Figure 5. Grain Size Distribution for CCR .................................................................... 13

Figure 6. Compilation of compaction test results .............................................................. 15

Figure 7. Hydraulic conductivity vs. pore volume plot for standard compacted CCR $\left(592.5 \mathrm{~kJ} / \mathrm{m}^{3}\right.$

Figure 8 . Hydraulic conductivity vs. pore volumes for $11 \%$ compacted $80 \% / 20 \% \mathrm{CCR} / \mathrm{MGro}^{\mathrm{TM}}$

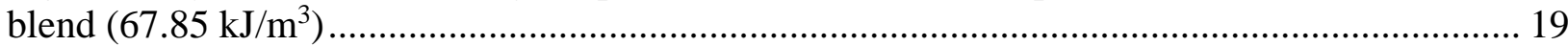

Figure 9. p-q plot for standard compacted CCR $\left(592.5 \mathrm{~kJ} / \mathrm{m}^{3}\right)$........................................... 20

Figure 10. Stress-Strain plot for standard compacted CCR $\left(592.5 \mathrm{~kJ} / \mathrm{m}^{3}\right)$........................... 21

Figure 11. p-q plot for $11 \%$ compacted 80/20 CCR/MGro ${ }^{\mathrm{TM}}$ blends $\left(67.85 \mathrm{~kJ} / \mathrm{m}^{3} \ldots \ldots \ldots \ldots \ldots \ldots . . . \ldots \ldots\right.$

Figure 12. Stress-Strain plot for $11 \%$ Compacted $80 \% / 20 \%$ CCR/MGro ${ }^{\mathrm{TM}}$ blend $\left(67.85 \mathrm{~kJ} / \mathrm{m}^{3}\right) 24$

Figure 13. p'-q' plot for $11 \%$ compacted $80 / 20 \mathrm{CCR} / \mathrm{MGro}{ }^{\mathrm{TM}}$ blend $\left(67.85 \mathrm{~kJ} / \mathrm{m}^{3}\right) \ldots \ldots \ldots \ldots \ldots . .26$

Figure 14. Pore-water pressure versus axial strain for $11 \%$ compacted $80 / 20 \mathrm{CCR} / \mathrm{MGro}{ }^{\mathrm{TM}}$ blend

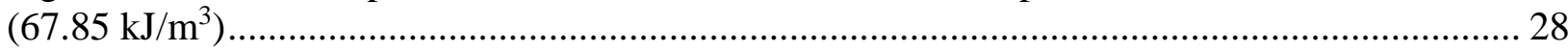

Figure 15. Image of Royal Scot plan including the location of slope profiles that are modeled

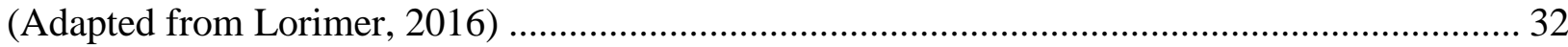

Figure 16. Day 3-Conventional Planar Slope (Ditch G) saturation with streamlines.................. 38

Figure 17. Day 4-Conventional Planar Slope (Ditch G) saturation with streamlines.................. 39

Figure 18. Day 15-Conventional Planar Slope (Ditch G) saturation with streamlines ................ 39

Figure 19. Day 25-Conventional Planar Slope (Ditch G) saturation with streamlines................ 40

Figure 20. Day 3-Geomorphic Slope (GLD-C) saturation with streamlines ............................. 41

Figure 21. Day 4-Geomorphic Slope (GLD-C) saturation with streamlines ............................. 42

Figure 22. Day 15-Geomorphic Slope (GLD-C) saturation with streamlines ........................... 42

Figure 23. Day 25-Geomorphic Slope (GLD-C) saturation with streamlines ........................... 43

Figure 24. Mean factor of safety/critical area for conventional planar slope (Ditch G)............ 45

Figure 25. Mean factor of safety/critical area for geomorphic slope (GLD-C) ........................ 46 


\section{List of Tables}

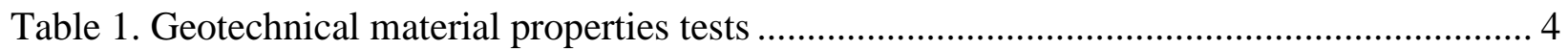

Table 2. List of Geotechnical testing values for CCR ............................................................... 6

Table 3. Testing conditions for standard compacted CCR $\left(592.5 \mathrm{~kJ} / \mathrm{m}^{3}\right)$................................ 10

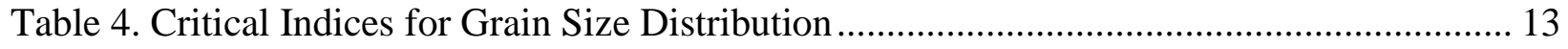

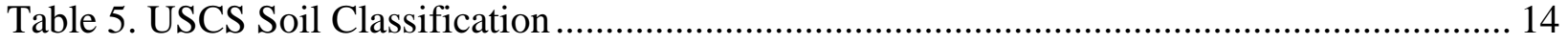

Table 6. Summary of compaction test results ........................................................................ 14

Table 7. Hydraulic Conductivity testing results for standard compacted CCR $\left(592.5 \mathrm{~kJ} / \mathrm{m}^{3}\right) \ldots . .16$

Table 8. Hydraulic Conductivity results for $11 \%$ Proctor $80 \% / 20 \%$ CCR/MGro ${ }^{\mathrm{TM}}$ blend $(67.85$

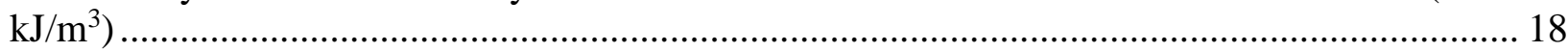

Table 9. Consolidated Undrained friction angle results for standard compacted CCR (592.5

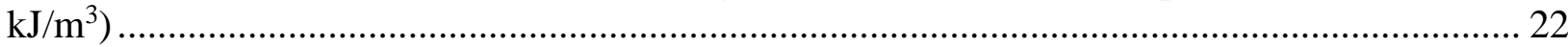

Table 10. Summary statistics for friction angle results (standard compacted CCR) $\left(592.5 \mathrm{~kJ} / \mathrm{m}^{3}\right)$

Table 11. Consolidated Undrained friction angle results for $11 \%$ Compacted $80 \% / 20 \%$

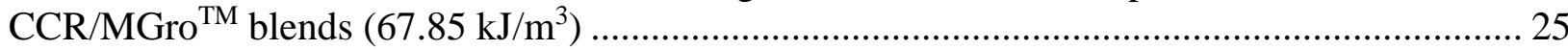

Table 12. Summary statistics for friction angle results (11\% Compacted 80\%/20\% CCR/MGro ${ }^{\mathrm{TM}}$

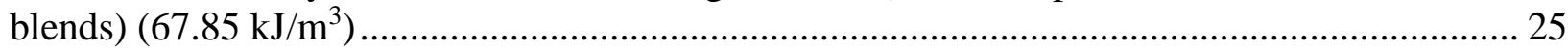

Table 13. Consolidated Undrained friction angle results for $11 \%$ compacted 80/20 blend (67.85

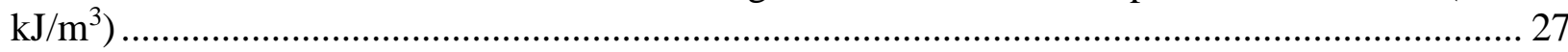

Table 14. Parameter summary table for Geotechnical lab testing ................................................. 29

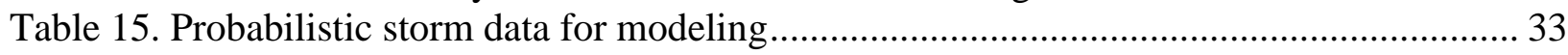

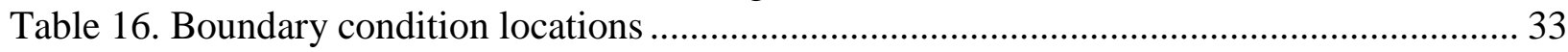

Table 17. Soil Water Characteristic Curve (SWCC) Parameters ................................................ 35

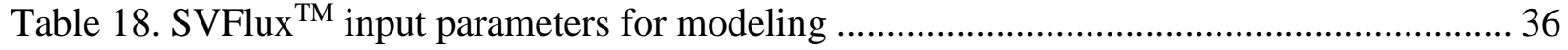

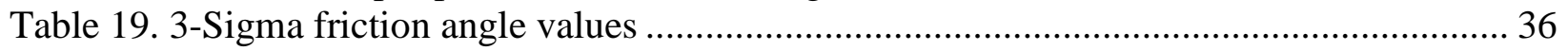

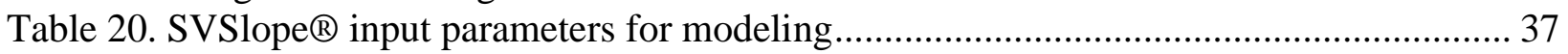

Table 21. Saturation of growth layer and hydraulic barrier........................................................... 38

Table 22. Saturation of growth layer and hydraulic barrier........................................................ 41

Table 23. Quantitative seepage/stability analysis for conventional planar slope (Ditch G) ......... 44

Table 24. Quantitative seepage/stability analysis for geomorphic slope (GLD-C) ....................... 44 


\section{Introduction/Background}

This study investigates the comparative differences between two primary amended soil designs for use in covering and capping the Royal Scot site located in Greenbrier County, West Virginia. This site is a bond forfeiture abandoned mine refuse site. The research performed consists of a geotechnical laboratory investigation on two amended refuse blends, and implement the geotechnical data into a two-dimensional (2D) Finite Element Modeling analysis consisting of slope stability coupled with seepage analysis. The two amended refuse specimens analyzed consisted of coarse coal refuse (CCR), and an $80 \% / 20 \%$ CCR/MGro ${ }^{\mathrm{TM}}$ blend material. The site is composed of an old abandoned coarse coal refuse facility. A map of the location of the Royal Scot site can be seen below in Figure 1 along with several other coal refuse facilities. The site has been abandoned since 1999 and exhibits many environmental issues (Ward, 2001). Some of these environmental issues consist of severe channel erosion and increased acid mine drainage. Royal Scot site has little to no vegetation, and uses a passive treatment facility to treat the acid mine drainage that leaches from the refuse fill.

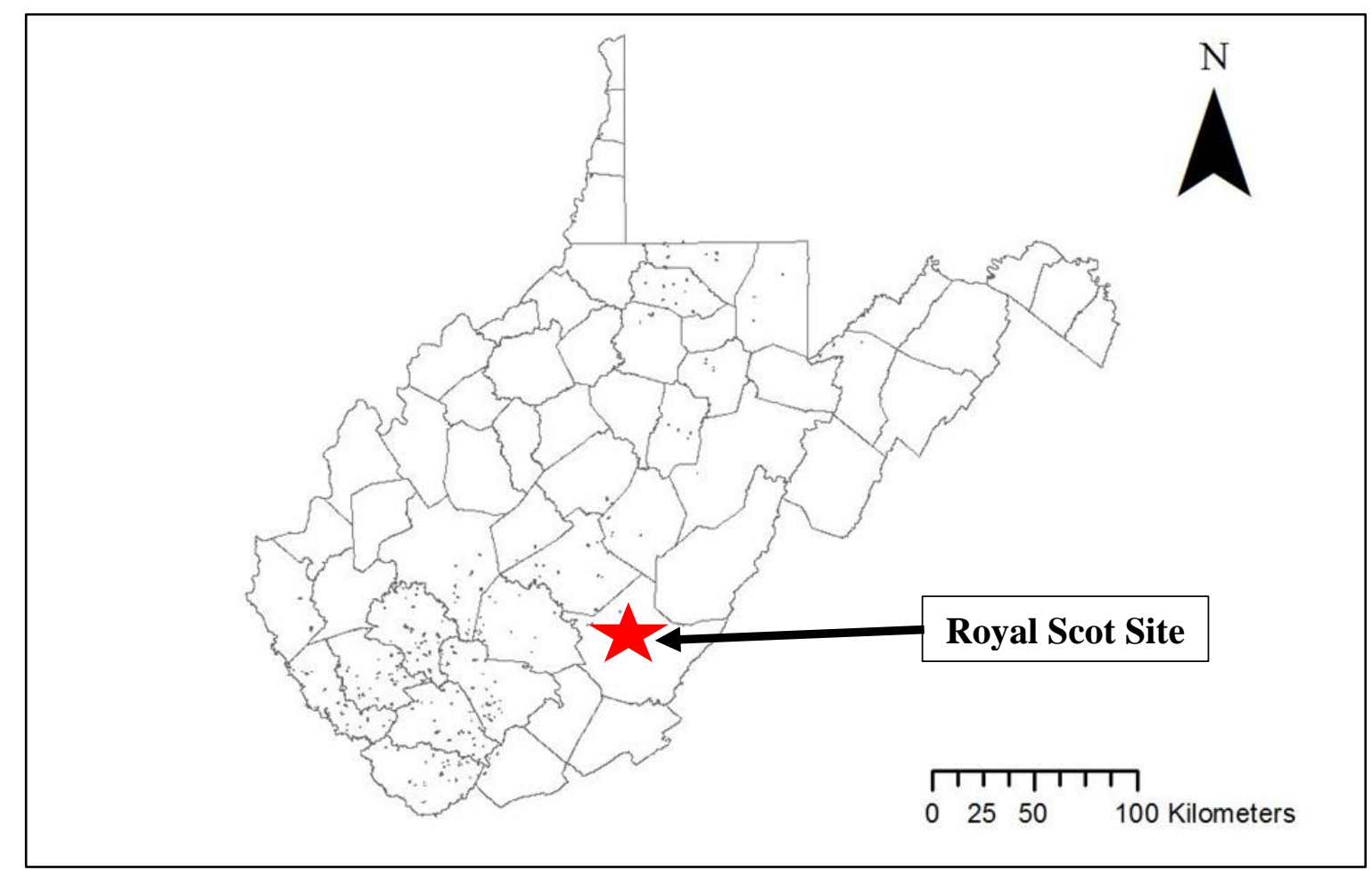

Figure 1. Location of Royal Scot site and several other coal refuse facilities (Stevens, 2016)

The site reclamation is proposed to be reclaimed by the West Virginia Department of Environmental Protection (WVDEP) following the geomorphic landform design (GLD) principle approach. GLD attempts to mimic the natural equilibrium of erosive forces found in mature 
landforms (Schor and Gray, 2007). As opposed to conventional reclamation techniques, GLD requires less maintenance and are more geotechnically stable (Nicolau, 2003). The motivation for this study was to use unsaturated 2D finite element modeling to gauge how the seepage/stability affects a GLD slope designs compared to conventional planar faced slopes with bench cut profiles.

The Royal Scot site has a previous proposed 60/40 CCR/MGro ${ }^{\mathrm{TM}}$ cap and cover design (Stevens, 2016). This system was composed of three layers including a fill material, compacted hydraulic barrier, and growth layer. The site also went under a hydraulic regrade design that included ditches for drainage of water, and GLD channels to reroute water to its corresponding watershed (Lorimer, 2016). The geometry from the hydraulic regrade could be accessed and used in the modeling procedure. The system was composed of three layers including a fill material, compacted hydraulic barrier, and growth layer. A cross-section of the previous proposed growth layer and hydraulic barrier can be seen in Figure 2. All layers are made up of coarse coal refuse (CCR). The CCR fill material will be the base of the cover, and then compacted CCR is used as the hydraulic barrier. The proposed cap and cover design uses a hydraulic barrier measuring 2 feet in thickness across the entire site for the GLD slopes, and a 2 to 1 -foot taper will be used from the crest to the toe of the conventional planar slope (Stevens, 2016). The upper part of the cap and cover system is the growth layer. The proposed growth layer is made up of 60\% coarse coal refuse and $40 \% \mathrm{MGro}^{\mathrm{TM}}$ material and is 1 foot thick across the entire site for this analysis.

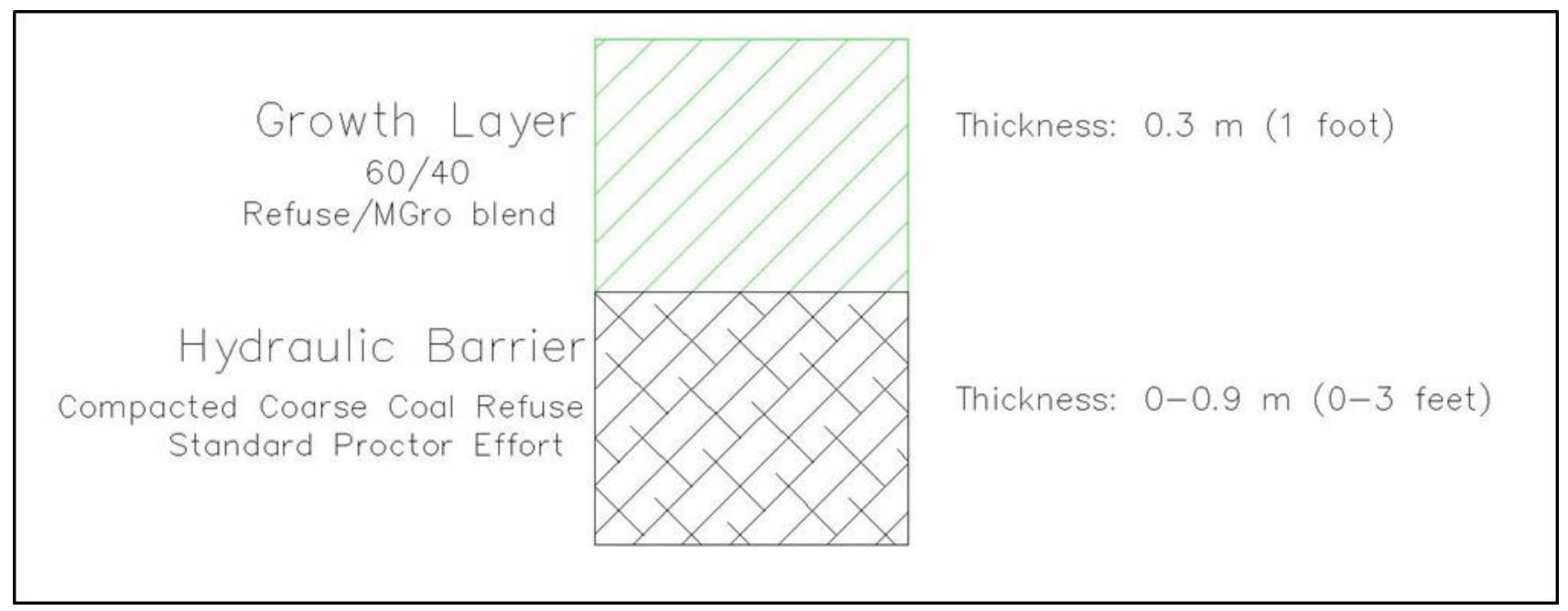

Figure 2. Cross-section of previous proposed growth layer and hydraulic barrier (Stevens, 2016)

As mentioned, $\mathrm{MGro}^{\mathrm{TM}}$ is used in the growth layer for the cap and cover design. $\mathrm{MGro}^{\mathrm{TM}}$ is a byproduct from a paper mill located in Covington, Virginia produced by WestRock ${ }^{\circledR}$. The material is created by solid residuals produced by the treatment of paper mill and carbon plant wastewater. Its composition is $85 \%$ solids from primary clarification of mill wastewater and $15 \%$ 
microbial biomass from biological wastewater treatment. MGro ${ }^{\mathrm{TM}}$ was also evaluated and recommended by (Daniels et al. 2013) as a soil amendment. An image of the MGro ${ }^{\mathrm{TM}}$ material is shown in Figure 3.

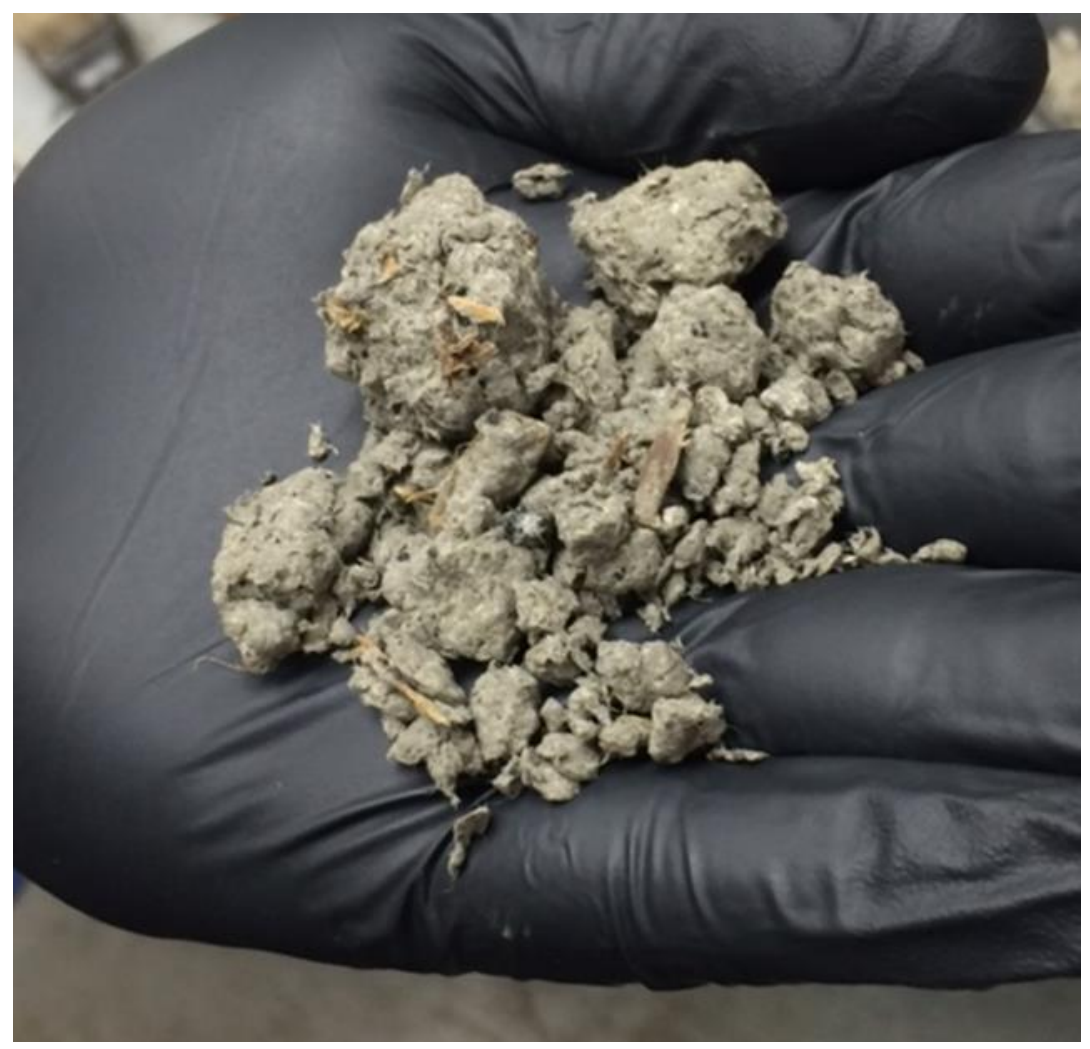

Figure 3. Image of typical MGro ${ }^{T M}$ sample

Since 2010 West Virginia University's Department of Civil and Environmental Engineering has researched geomorphic landform design (GLD) for application in Central Appalachia. Some of the accomplishments include conceptual GLD on a permitted valley fill; geotechnical slope stability evaluation of GLDs for steep terrain; evaluation of differences in groundwater seepage between conventional planar and geomorphic landform designs; and comparisons of hydrologic response (DePriest, 2015). The goal of this projects is to evaluate the use of GLD for Appalachian coal field reclamation, and determine if the approach is cost effective for the region. If proven successful, the citizens and State of West Virginia will benefit from GLD model through reduced environmental impact, improved water quality, and improved flood control. 


\section{Purpose}

The purpose of this research is to optimize an alternative cap blend ratio mixture for the reclamation of a coarse coal refuse pile located in central Appalachia. An 80/20 CCR/MGro ${ }^{\mathrm{TM}}$ growth blend will be analyzed for economic savings and performance compared to a previous proposed 60/40 CCR/MGro ${ }^{\mathrm{TM}}$ growth blend. The goal of this research is to reduce construction costs and reduce seepage into the refuse pile due to the generation of acid rock drainage/acid mine drainage into to nearby streams originating from the Royal Scot refuse site.

\section{Objective}

The objective of this study is to perform laboratory testing on refuse and MGro ${ }^{\mathrm{TM}}$ blend specimens, and evaluate that data to perform computer based Finite Element Modeling (FEM). Slope stability and seepage modeling will be done to gauge performance criterion. The results from the computer modeling can be used to quantify design values to compare with the proposed cap and cover design.

\section{Scope of Work}

The scope of work is separated into three tasks.

\section{Task 1-Geotechnical Lab Testing}

Geotechnical laboratory testing was performed on two specimen types. The first specimen is coarse coal refuse which is found on the Royal Scot site. The second specimen is the 80/20 $\mathrm{CCR} / \mathrm{MGro}^{\mathrm{TM}}$, which is proposed as an alternative cap and cover system to the proposed design. Laboratory testing was performed on these two specimens to obtain their geotechnical index and performance properties for comparative analysis. Table 1 presents the testing procedure performed and its corresponding American Society of Testing Materials protocol.

\section{Table 1. Geotechnical material properties tests}

\begin{tabular}{|c|c|}
\hline Test Name & ASTM \\
\hline $\begin{array}{c}\text { Grain Size Distribution } \\
\text { (GSD) }\end{array}$ & D-422 \\
\hline Compaction & D-698 \\
\hline Hydraulic Conductivity & D-5084 \\
\hline $\begin{array}{c}\text { Triaxial Isotropic } \\
\text { Consolidated } \\
\text { Undrained Strength (ICU) }\end{array}$ & D-4767 \\
\hline
\end{tabular}

\section{Task 2-2D Finite Element Analysis}

Task 2 involves performing 2-D analysis on a conventional planar and geomorphic slope profile. After completion of the laboratory testing, the properties are used for Finite Element Modeling. The modeling will involve assessment of infiltration/seepage and slope stability to gauge the cap and cover system performance. 


\section{Task 3-Evaluation of Results}

The last task is to evaluation of the Finite Element Analysis. Evaluating the modeling involves analysis of saturation/pore water pressure, infiltration into the slope profile, and if the slopes are stable under a worst-case scenario storm. This involves comparing/contrasting the modeling to the proposed design to determine if acid mine drainage can be reduced.

\section{Literature Review}

\section{Geomorphic Landform Design}

Geomorphic landform design (GLD) is a new landforming technique that has become prominent in mine reclamation. The studies for GLD began in the early 2000's (Nicolau, 2003). GLD differs from conventional landforming in terrain profile, stability, and erosion/water management. Conventional landforms typically consist of steep slope profiles with benches to alleviate driving forces. GLD profiles implement the principle of geomorphology to create a terrain that is similar to its former natural landform (Nicolau, 2003).

Research has also shown that GLD slopes have higher factors of safety in regard to slope stability. Russell et al. (2014) performed slope stability analysis on geomorphic and conventional slope profiles in Southern West Virginia. The geomorphic profiles proved to have higher factors of safety (2.04-3.49) compared to conventional designs (1.25-1.67). Russel et al. (2014) states that the reason for increased stability in geomorphic slopes is due to its shallow profiles compared to steep profiles that are prevalent in conventional slopes.

Another study on GLD was performed in Southern West Virginia on erosion/water management by DePriest et al. (2015). The study was performed on steep terrain that mimic a surface mine site. The geomorphic designs showed potential for decreased erosion, and improvement of water management/transport on the site according to DePriest et al. (2015).

\section{Short Paper Fiber}

Short paper fiber (SPF) is a by-product from water treatment at paper mills. The material is derived from paper making materials such as wood, fiber, clay, and organic matter. The SPF for this research is produced by WestRock ${ }^{\circledR}$ and is marketed as MGro ${ }^{\mathrm{TM}}$. Recent studies have shown that SPF has the capabilities to be used as a soil amendment. Carpenter and Fernandez (2000) mixed paper mill sludge with topsoil. The combination of the sludge and soil were able to produce vegetative growth. The WestRock ${ }^{\circledR} \mathrm{MGro}^{\mathrm{TM}}$ has also been able to serve as a vital soil amendment for growth according to Daniels et al. (2003).

SPF blends have been applied in West Virginia for coal refuse reclamation purposes. Laubenstein (2004) used a SPF/topsoil cover along the Tygart River. The blended material was used as the cover material. Water quality greatly improved with the use of the SPF/topsoil cover, and prove to beneficial for coal refuse reclamation purposes (Laubenstein, 2004). 


\section{Geotechnical Laboratory Testing}

The use of CCR in impoundments/dams dates back to the late 1970's. The refuse is commonly used to construct dams to retain a slurry of fine coal refuse (FCR) and water (Hegazy et al. 2004). These impoundments can be found throughout West Virginia, Pennsylvania, Ohio, Virginia, and Kentucky. Throughout each state the CCR shale varies due to regional geologic conditions, and coal mining/preparation processes (D'Appolonia, 2009). A list of geotechnical testing for index and strength for CCR can be seen in Table 2.

Table 2. List of Geotechnical testing values for CCR

\begin{tabular}{|c|c|c|c|c|c|c|}
\hline \multicolumn{7}{|c|}{ Coarse Coal Refuse (CCR) Laboratory Testing Values } \\
\hline \multirow{2}{*}{ Reference } & Location & \multicolumn{7}{c|}{$\begin{array}{c}\text { Effective Shear } \\
\text { Strength }\end{array}$} \\
\cline { 3 - 7 } & & $\begin{array}{c}\mathrm{D}_{30} \\
(\mathrm{~mm})\end{array}$ & $\begin{array}{c}\mathrm{D}_{50} \\
(\mathrm{~mm})\end{array}$ & $\begin{array}{c}\mathrm{D}_{60} \\
(\mathrm{~mm})\end{array}$ & $\begin{array}{c}\text { Passing } \\
200 \\
\text { Sieve }(\%)\end{array}$ & $\varphi^{\prime}($ degrees) \\
\hline $\begin{array}{c}\text { Almes and Butail } \\
\text { (1976) }\end{array}$ & $\begin{array}{c}\text { PA, WV, } \\
\text { KY, VA }\end{array}$ & 0.7 & 2.5 & 4.5 & 10 & $33-39$ \\
\hline McCutcheon (1981) & OH & 1.9 & 4.5 & 7 & 7 & 36 \\
\hline Saxena et al. (1984) & WV & 12 & 16 & 22 & 2 & $27-40$ \\
\hline Albuquerque (1994) & VA & 3.5 & 7.5 & 12 & 1.5 & 39 \\
\hline Hegazy et al. (2004) & PA & 0.35 & 1.23 & 2.02 & 19.8 & 34 \\
\hline
\end{tabular}

As mentioned CCR varies due to its regional geography and processes it undergoes. Table 2 shows values for grain size that vary greatly. According to Hegazy et al. (2004), 19.8\% passed the \#200 sieve, which classifies as clays/silts. This is much larger than what was seen in the other research as all other CCR testing showed less than 10\% passed the \#200 sieve. This large increase in fines is accredited to advances in coal mining and preparation processes over the last 15 years, which resulted in a trend toward greater percentages of fines in CCR (D'Appolonia, 2009). Table 2 also shows effective shear strength friction angle values for different regions. The data shows that CCR is variable when it comes to friction angle. In West Virginia, the angle can range from 27-40 degrees, which is highly variable. (Saxena et al. 1984). The other regions show that the friction angle varies from 33 to 39 degrees. 


\section{Materials and Methods}

As mentioned in Task 1, geotechnical lab testing was performed on two separate soil specimens. Coarse coal refuse (CCR) and $\mathrm{MGro}^{\mathrm{TM}}$ were the two materials that underwent lab testing. The testing was done according to the most recent ASTM standards. Table 1 shows the ASTM standards and their corresponding designation. The goal of the geotechnical laboratory testing was to gain the two materials geotechnical indexes and performance properties to compare to previous studies.

\section{Grain Size Distribution}

The first set of testing was acquiring the grain size distribution (GSD) of the CCR shale material. GSD was done according to ASTM D-422. The material that was analyzed was CCR obtained from the Royal Scot site. The soil was obtained using a $3 / 4 \mathrm{in}$. sieve (19 mm opening) in the field. The GSD allows gives useful indexes such as the coefficient of uniformity $\left(\mathrm{C}_{\mathrm{u}}\right)$ and coefficient of gradation $\left(\mathrm{C}_{\mathrm{c}}\right)$. These indexes allow the CCR to be classified into its United Soil Classification System (USCS) soil classification.

\section{Compaction Testing}

Compaction testing was the next testing procedure to gain the unit weights of CCR and the 80/20 blend material. Compaction testing was performed according to ASTM D-698 to find the dry unit weight of two materials. The tests were performed at $11 \%$ Standard Proctor compaction $\left(67.85 \mathrm{~kJ} / \mathrm{m}^{3}\right.$ compaction energy). The two test that were performed are as follows:

1. Coarse Coal Refuse at $11 \%$ Proctor Energy $\left(67.85 \mathrm{~kJ} / \mathrm{m}^{3}\left(1,425 \mathrm{ft}-\mathrm{lb} / \mathrm{ft}^{3}\right)\right)$

2. $80 \% / 20 \%$ CCR/MGro ${ }^{\mathrm{TM}}$ Blend at $11 \%$ Proctor Energy $\left(67.85 \mathrm{~kJ} / \mathrm{m}^{3}\left(1,425 \mathrm{ft}-\mathrm{lb} / \mathrm{ft}^{3}\right)\right)$

The coarse coal refuse at $11 \%$ proctor was completed to find the correct moisture content and dry unit weight so the blend material could be compacted. The blend material was completed on a by volume basis using a one cup vessel for each test (i.e. 20 cups=16 cups CCR +4 cups MGro ${ }^{\mathrm{TM}}$ ). The blend was then mixed in a blender at $11 \% \mathrm{CCR}$ proctor moisture content.

\section{Hydraulic Conductivity}

Hydraulic conductivity testing was performed according to ASTM D-5084 (Flexible Wall permeability testing) for two specimens:

1. Coarse Coal Refuse at Standard Proctor Energy $\left(592.5 \mathrm{~kJ} / \mathrm{m}^{3}\right)$

2. $80 \% / 20 \% \mathrm{CCR} / \mathrm{MGro}^{\mathrm{TM}}$ Blend at $11 \%$ Proctor Energy $\left(67.85 \mathrm{~kJ} / \mathrm{m}^{3}\right)$

Flexible wall was chosen over rigid wall testing due to the possibility of particle migration that is prevalent in rigid wall permeability.

The standard Proctor CCR was compacted at a target density of $15.9 \mathrm{kN} / \mathrm{m}^{3}$ and $14.3 \%$ moisture content, while the growth blend target density was $11.2 \mathrm{kN} / \mathrm{m}^{3}$ and $31.9 \%$ moisture. A hydraulic gradient of $i=15$ was used for standard compacted testing. A hydraulic gradient of 15 is not 
recommended by ASTM, but was needed to accelerate the time of the testing procedure. A hydraulic gradient of $\mathrm{i}=15$ was also used to achieve the same accelerated testing for the growth blend. Triplicate testing was done for both standard compacted, and $11 \%$ compacted samples to ensure accuracy. The testing procedure was done until the readings achieved a steady state. Steady state means the parameters were constant and allowed to reach a steady flowrate. Once each test reached a steady state, the hydraulic conductivity could be determined based on the last five measurements that were taken.

\section{Triaxial Strength Testing}

For strength testing, isotropic consolidated undrained (ICU) triaxial testing was performed. The specimens that were tested include the standard compacted CCR and 11\% compacted 80/20 MGro $^{\mathrm{TM}}$ materials. A GeoTac Sigma 1 triaxial device was used for this testing procedure. Figure 4 shows the set-up of the triaxial machine with specimen in flex-wall.

In order to account for pore water pressure build-up in the slopes, consolidated undrained (ICU) tests were run in accordance with ASTM D-4767. ICU triaxial testing simulates a worst-case scenario. This test allows the soil specimen to consolidate under specified stress conditions, and then sheared with drainage valves closed to simulate an undrained state. This may not be the case for the field site, but $\mathrm{CU}$ results will give conservative values for analysis. 


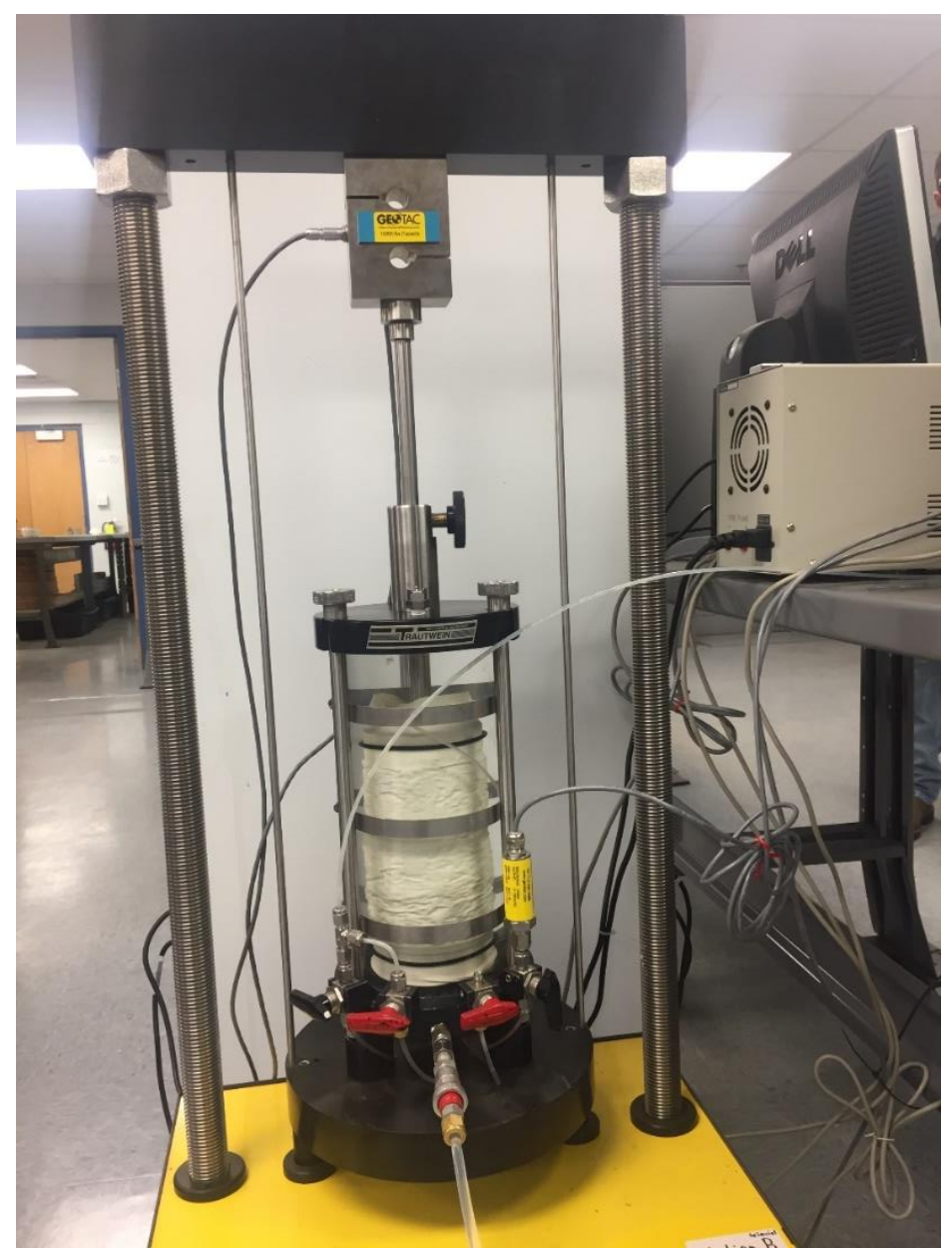

Figure 4. Display of the ICU triaxial test

\section{Standard Compacted CCR $\left(592.5 \mathrm{~kJ} / \mathrm{m}^{3}\right)$}

Standard Proctor Compacted CCR was tested $\left(592.5 \mathrm{~kJ} / \mathrm{m}^{3}\right)$ for shear strength under two different confining pressures The CCR gradation was passing a $19 \mathrm{~mm}(3 / 4 \mathrm{in}$.) sieve which was the same as GSD. These conditions were chosen as a worst-case scenario. The first confining pressure chosen was a middle failure which corresponded to $24.38 \mathrm{~m}$ (80.0 feet) into the slope. The second confining pressure simulated a deep failure of $36.58 \mathrm{~m}$ (120 feet) into the slope profile. For the two worst-case conditions, a soil density of $15.71 \mathrm{kN} / \mathrm{m}^{3}\left(100 \mathrm{lb} / \mathrm{ft}^{3}\right)$ was used to estimate the stress condition for ICU testing. This density was chosen to simulate the average of different compaction efforts that may likely be found at the Royal Scot site. 
Table 3. Testing conditions for standard compacted CCR $\left(592.5 \mathrm{~kJ} / \mathrm{m}^{3}\right)$

\begin{tabular}{|c|c|c|}
\hline \multirow{2}{*}{$\begin{array}{c}\text { Testing } \\
\text { Conditions }\end{array}$} & Depth & $\begin{array}{c}\text { Confining } \\
\text { Pressure }\end{array}$ \\
\cline { 2 - 3 } & $\mathrm{m}(\mathrm{ft})$ & $\mathrm{kPa}\left({\left.\mathrm{lb} / \mathrm{in}^{2}\right)}^{2}\right.$ \\
\hline & 24.38 & 386 \\
1 & $(80.0)$ & $(56)$ \\
\hline & 36.58 & 572 \\
2 & $(120)$ & $(83)$ \\
\hline
\end{tabular}

This sweep of isotropic CU testing will be used in the analysis for the hydraulic barrier. The barrier will not be at the specified depths listed in Table 3, but these serve as a conservative estimate to the strength of the CCR at depths found within the site and give insight on how the barrier will perform at a worst-case scenario.

Before the triaxial testing process, the specimens went through permeability testing, so they were near full saturation $(61 \%, 63 \%, 84 \%)$, and no back pressure was done for the CU testing. Bypassing the back-pressure procedure, the specimens went straight from seating to the consolidation phase at the specified confining pressures listed in Table 3. During consolidation, the specimens were under isotropic stress with drainage valves open to allow a change in void ratio.

After completion of isotropic consolidation, the specimens could be sheared. Drainage valves were closed during shearing in accordance with a $\mathrm{CU}$ test, allowing no pore water pressure to escape. A constant rate of shear was used with a strain rate of $2 \%$ per hour until it reached $20 \%$ strain. A pressures sensor was placed on one of the drainage valves to track pore water pressure.

\section{Total Stress Analysis}

To calculate friction angles and discover at what strain rate the specimens failed a total stress analysis was used for the standard compacted CCR. For a total stress analysis, stress paths have to be analyzed to discover the materials friction angle and at what strain rate the material failed. The parameters "p" and "q" are defined in equations 1 and 2 for total stress. Equations 1 and 2 are taken from the USACE Manual No. 1110-2-1902 (2003).

$p=\frac{\sigma_{1}+\sigma_{3}}{2}$

(Equation 1)

$q=\frac{\sigma_{1}-\sigma_{3}}{2}$

(Equation 2) 


\section{Failure Criterion}

Sigma 1 and Sigma 3 are defined as the major and minor principal stresses in a Mohr Coulomb plot. Sigma 1 in this testing is the axial stress applied by the piston, and sigma 3 is the confining pressure. The $p-q$ plot is a representation of the center and radius of Mohr's circle and can help calculate the internal angle of friction. Since the material is classified as a coarse sand, cohesion is assumed to be equal to zero.

\section{$11 \%$ 80/20 CCR/MGro ${ }^{\mathrm{TM}}\left(67.85 \mathrm{~kJ} / \mathrm{m}^{3}\right)$}

The $11 \%$ compacted $80 / 20$ blend underwent the same ICU triaxial testing that the standard compacted CCR underwent, but with much different confining pressures. The blend material had confining pressures of 34.5 and $69 \mathrm{kPa}$ (5 and $10 \mathrm{psi}$ ) versus 386 and $572 \mathrm{kPa}(56$ and $83 \mathrm{psi}$ ). These stresses were low as the growth/blend layer is only designed to be one foot thick. These pressures are overestimates as was the standard compacted CCR for worst-case scenario. The four specimens underwent the same permeability testing as the standard compacted CCR to reach near or at full saturation ( $\mathrm{i}=15)$. After completing reaching a steady state hydraulic conductivity, the specimens could then be placed on the triaxial machine to undergo seating and isotropic consolidation at the 34.5 and $69 \mathrm{kPa}$ confining pressure. The test followed the same procedure for shear with the drainage valves closed to not allow any dissipation, and following an "undrained" condition. The same strain rate of $2 \%$ per hour until reaching $20 \%$ strain was used for the 80/20 testing.

Two different methods of analysis were used to determine friction angle and failure for the 80/20 blends. A total stress analysis was attempted for the $80 / 20$ blends. This was the same method that was used for the standard compacted CCR, but some issues arose with the stress paths, and their behavior, so a new approach was taken. The other method that was used for analysis was an effective stress analysis. The major difference between a total and effective stress analysis is the subtraction of the pore water pressure from the major and minor principal stresses. Equations 3 and 4 show the parameters $\mathrm{p}^{\prime}$ and $\mathrm{q}^{\prime}$ which govern an effective stress analysis. The (') indicates that the major and minor principal stresses (Sigma 1 and Sigma 3) subtract out the pore-water pressure (u) indicating an "effective" stress analysis. Equations 3 and 4 are taken from the USACE Manual No. 1110-2-1902 (2003).

$$
\begin{aligned}
& p^{\prime}=\frac{\sigma_{1^{\prime}+\sigma_{3}{ }^{\prime}}}{2} \\
& q^{\prime}=\frac{\sigma_{1}^{\prime}-\sigma_{3}{ }^{\prime}}{2}
\end{aligned}
$$


The reason for using an effective stress analysis is the behavior of $\mathrm{MGro}^{\mathrm{TM}}$ in the 80/20 blends. As the piston compresses the sample, it is expected the material would also compress. That is not the case with the $80 / 20$ blend. The MGro ${ }^{\mathrm{TM}}$ material cause the sample to undergo dilation or it causes the sample to extend as the piston is compressed. The effective stress analysis also allows the lightly compacted blend material to consolidate. The $\mathrm{MGro}^{\mathrm{TM}}$ portion of the blend, went under isotropic consolidation under a confined pressure. As the sample was confined, water would leave the $\mathrm{MGro}^{\mathrm{TM}}$ material, but did not have any path due, which would lead to the sample to undergo dilation.

\section{Results}

\section{Grain Size Distribution}

Figure 5 shows the Grain Size Distribution for the coarse coal refuse shale material. GSDs classify the material on the basis of gravels, sands, silts/clays. The plot lists all particle sizes and the following U.S. Standard Sieve Size. The two tests that were performed show consistent results for GSD 1 and GSD 2 with only small minor differences in the sand portion.

After performing the GSD, the shale material could then be classified according to the United Soil Classification System (USCS)-ASTMD-2487. The two GSD tests performed show that the material was on the border of a gravel and sand. Over $50 \%$ of the material passes the \#4 sieve classifying it as a sand. The gradation curve also shows that there are less than $5 \%$ fines and greater than $15 \%$ gravel classifying the material as well graded sand with gravel (SW), but is on the verge of being poorly graded due to the coefficient of gradation. 


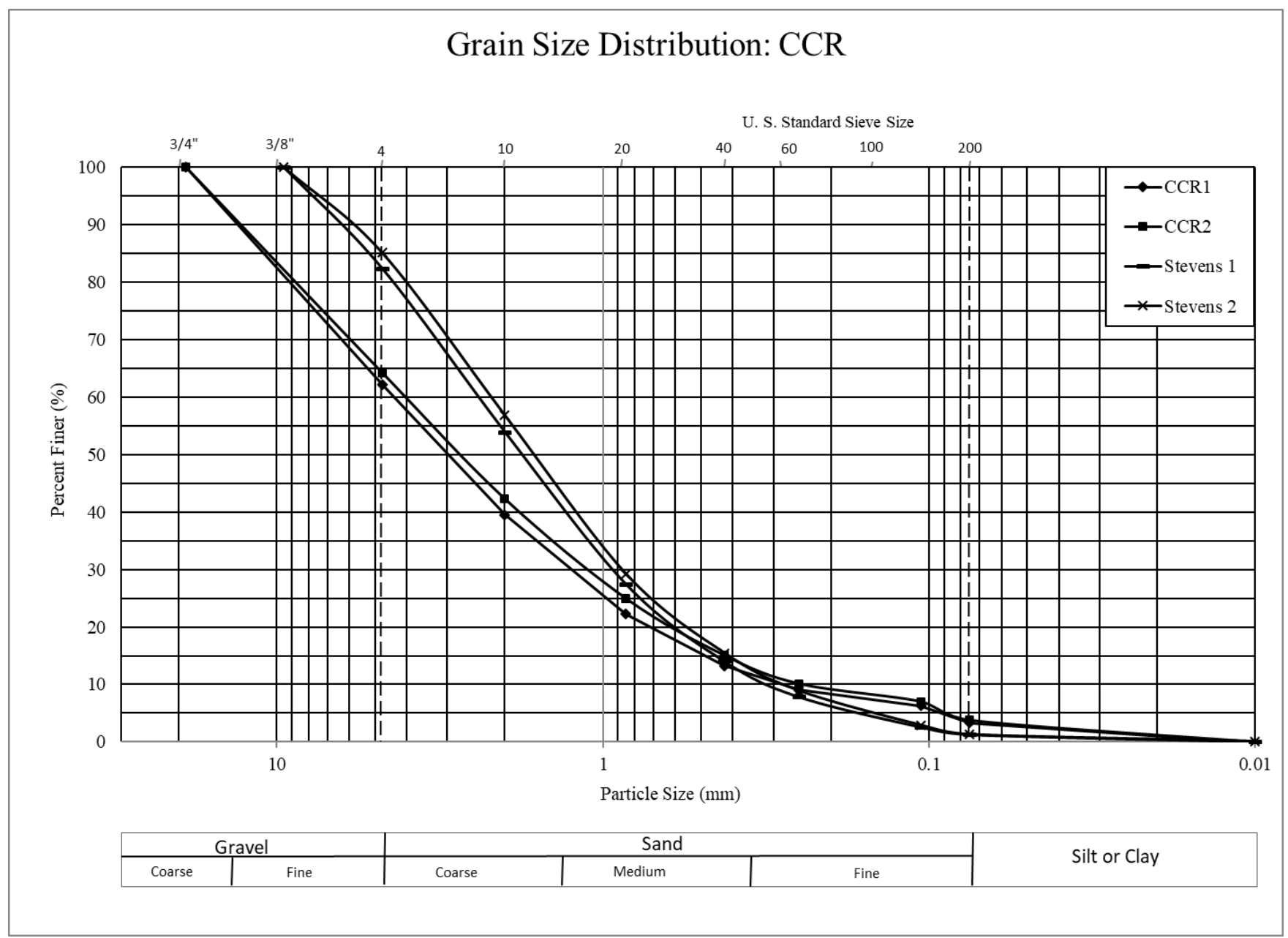

Figure 5. Grain Size Distribution for CCR

Table 4. Critical Indices for Grain Size Distribution

\begin{tabular}{|c|r|r|r|}
\hline Results & CCR1 & CCR2 & Average \\
\hline $\mathbf{D}_{\mathbf{9 0}}(\mathbf{m m})$ & 10.40 & 10.40 & 10.40 \\
\hline $\mathbf{D}_{\mathbf{6 0}}(\mathbf{m m})$ & 4.40 & 4.00 & 4.20 \\
\hline $\mathbf{D}_{\mathbf{5 0}}(\mathbf{m m})$ & 3.00 & 2.90 & 2.95 \\
\hline $\mathbf{D}_{\mathbf{3 0}}(\mathbf{m m})$ & 1.40 & 1.20 & 1.30 \\
\hline $\mathbf{D}_{\mathbf{2 5}} \mathbf{( m m )}$ & 1.00 & 0.85 & 0.93 \\
\hline $\mathbf{D}_{\mathbf{1 0}}(\mathbf{m m})$ & 0.29 & 0.27 & 0.28 \\
\hline Cu-Coefficient of Uniformity & 15.17 & 14.81 & 14.99 \\
\hline Cc-Coefficient of Gradation & 1.54 & 1.33 & 1.43 \\
\hline
\end{tabular}


Table 5. USCS Soil Classification

\begin{tabular}{|c|c|}
\hline $\begin{array}{c}\text { USCS Soil } \\
\text { Classification }\end{array}$ & $\begin{array}{c}\text { Group } \\
\text { Symbol }\end{array}$ \\
\hline $\begin{array}{c}\text { Well graded sand } \\
\text { with gravel }\end{array}$ & $\mathrm{SW}$ \\
\hline
\end{tabular}

\section{Compaction Testing}

Table 6 gives a summary of the optimum dry unit weight and corresponding moisture contents. A compilation of the compaction curves is given in Figure 6 with zero air void lines and $90 \%$ saturation lines for each compaction curve.

Table 6. Summary of compaction test results

\begin{tabular}{|c|c|c|}
\hline Compaction Energy & $\begin{array}{c}\text { Optimum Dry Unit } \\
\text { Weight }\left(\mathbf{k N} / \mathbf{m}^{\mathbf{3}}\right)\end{array}$ & $\begin{array}{c}\text { Optimum Moisture } \\
\text { Content }(\mathbf{\%})\end{array}$ \\
\hline $\begin{array}{c}\text { CCR } 11 \% \text { Proctor } \\
\left(67.85 \mathrm{~kJ} / \mathrm{m}^{3}\right)\end{array}$ & 13.07 & 11.8 \\
\hline $\begin{array}{c}80 / 20 \mathrm{MGro} \text { Blend } \\
11 \% \text { Proctor }(67.85 \\
\left.\mathrm{kJ} / \mathrm{m}^{3}\right)\end{array}$ & 11.20 & 31.9 \\
\hline
\end{tabular}




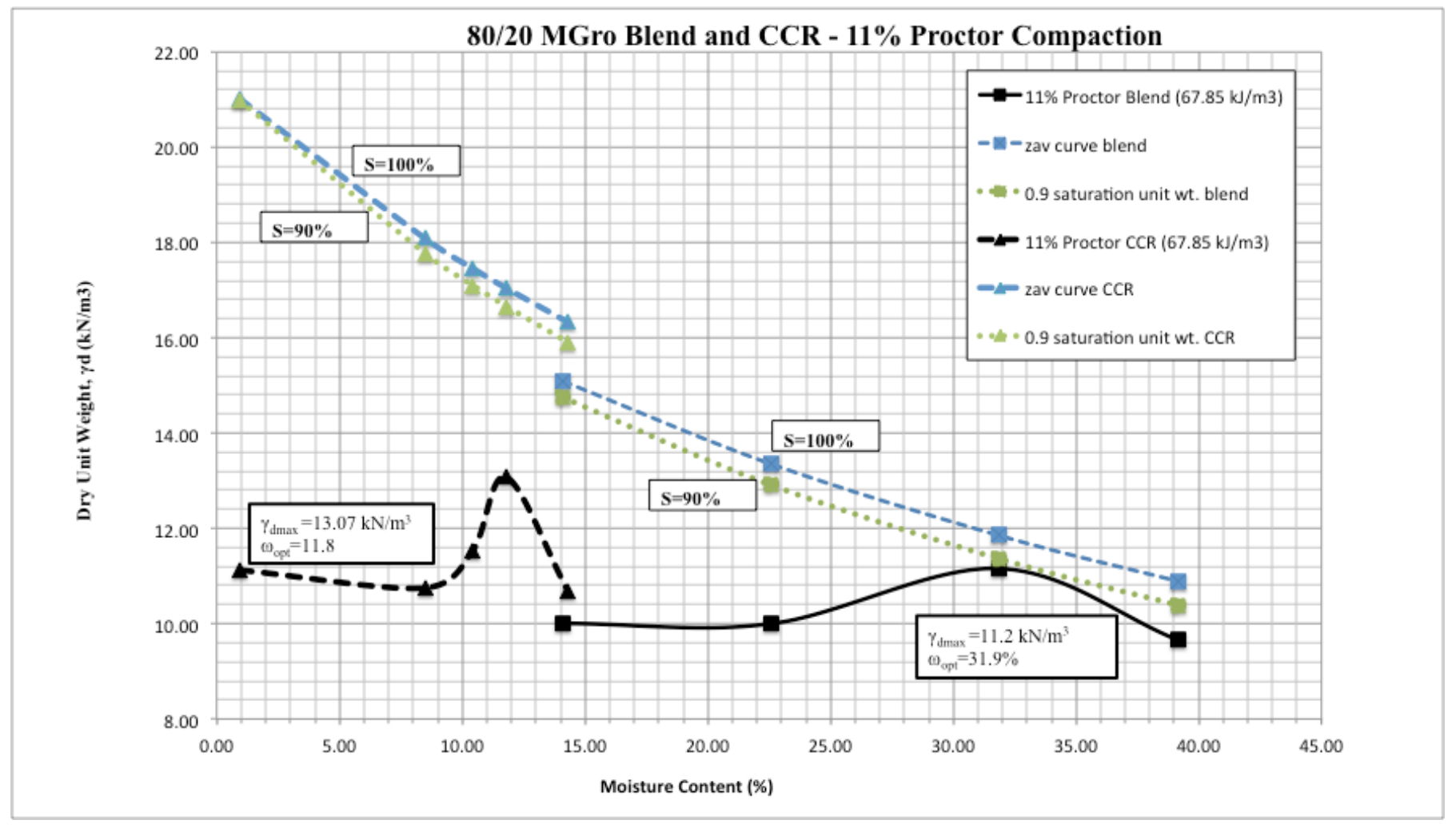

Figure 6. Compilation of compaction test results

The CCR curve at $11 \%$ Proctor shows that at low moisture content the material loses a small amount of density until it reaches $8.5 \%$. From that point, it increases its density until reaching an optimum density of $13.07 \mathrm{kN} / \mathrm{m}^{3}$ at $11.8 \%$ moisture. The blended material is at a much higher moisture content than the CCR. This can be attributed to MGro ${ }^{\mathrm{TM}}$ ability absorb large volumes of water. The curve starts at $15 \%$ moisture and maintains a constant density until $22.5 \%$ moisture. From that point the density increases gradually as moisture content also increases. The blended material reaches an optimum density of $11.2 \mathrm{kN} / \mathrm{m}^{3}$ at $31.9 \%$ moisture content.

There is a $1.87 \mathrm{kN} / \mathrm{m}^{3}$ decrease in density from the CCR test to the blended material. This can be attributed to the $\mathrm{MGro}^{\mathrm{TM}}$ material retaining more water, and creating an almost sludge-like finished product at much higher moisture content. The CCR is able to take in the water better and is much drier at its optimum density as can be seen in Figure 6. 


\section{Hydraulic Conductivity Testing}

\section{Standard Proctor CCR Tests $\left(592.5 \mathrm{~kJ} / \mathrm{m}^{3}\right)$}

Three tests were prepared at standard Proctor compaction $\left(592.5 \mathrm{~kJ} / \mathrm{m}^{3}\right)$. These tests were targeted to reach a density of $15.9 \mathrm{kN} / \mathrm{m}^{3}$ and water content of $14.3 \%$. The data and corresponding hydraulic conductivity can be seen in Table 7 below. These tests ranged from $10^{-6}$ to $10^{-7} \mathrm{~cm} / \mathrm{s}$ that is common for coarse coal refuse. The test also proved to be accurate on the last five measurements as they show a coefficient of variation within $10 \%$.

Table 7. Hydraulic Conductivity testing results for standard compacted CCR $\left(592.5 \mathrm{~kJ} / \mathrm{m}^{3}\right)$

\begin{tabular}{|c|c|c|c|c|c|c|}
\hline Test & $\begin{array}{c}\text { Water } \\
\text { Content }(\%)\end{array}$ & $\begin{array}{c}\text { Dry Unit } \\
\text { Weight } \\
\left(\mathbf{k N} / \mathbf{m}^{3}\right)\end{array}$ & $\begin{array}{c}\text { Degree of } \\
\text { Saturation } \\
\text { (S) }\end{array}$ & $\begin{array}{c}\text { Porosity } \\
\text { (n) }\end{array}$ & $\begin{array}{c}\text { Hydraulic } \\
\text { Conductivity } \\
\text { Average (Last } 5 \\
\text { Points) }(\mathrm{cm} / \mathrm{s})\end{array}$ & $\begin{array}{c}\text { Coefficient of } \\
\text { Variation } \\
\text { (Last } 5 \text { points) } \\
(\mathbf{c m} / \mathbf{s})\end{array}$ \\
\hline 1 & 14.21 & 15.7 & $84 \%$ & 0.27 & $3.83 \times 10^{-7}$ & 0.0980 \\
\hline 2 & 15.01 & 13.9 & $61 \%$ & 0.35 & $1.15 \times 10^{-6}$ & 0.0783 \\
\hline 3 & 15.51 & 13.9 & $63 \%$ & 0.35 & $7.24 \times 10^{-7}$ & 0.0454 \\
\hline
\end{tabular}

The hydraulic conductivity of the specimens is plotted against the pore volume. Pore volume is defined as the porosity multiplied by the total specimen volume. The plot can be seen in Figure 7. A minimum of 1 pore volume was required to go through the specimen to ensure that full saturation had occurred, and a stable filter condition was achieved. Test 1 shows a large gap between 0 and 0.52 pore volumes. This is because a reading was not taken between 0 and $75 \mathrm{~mL}$ of water from the test. As can be seen in Figure 7, the test achieved a steady state with little variation in the data points. Test 2 had some fluctuations for the first 6 points, but quickly reach a steady state as it reached one pore volume. Test 3 had little fluctuation in the data, and quickly reached a steady state with almost no change in data points after 0.40 pore volumes. Test 1 tended to be slightly slower than tests 2 and 3 as can be seen in the plot. This is a direct cause to the dry unit wet being on the wetter side of optimum as indicated by the dry unit weight, and moisture content in Table 7. 


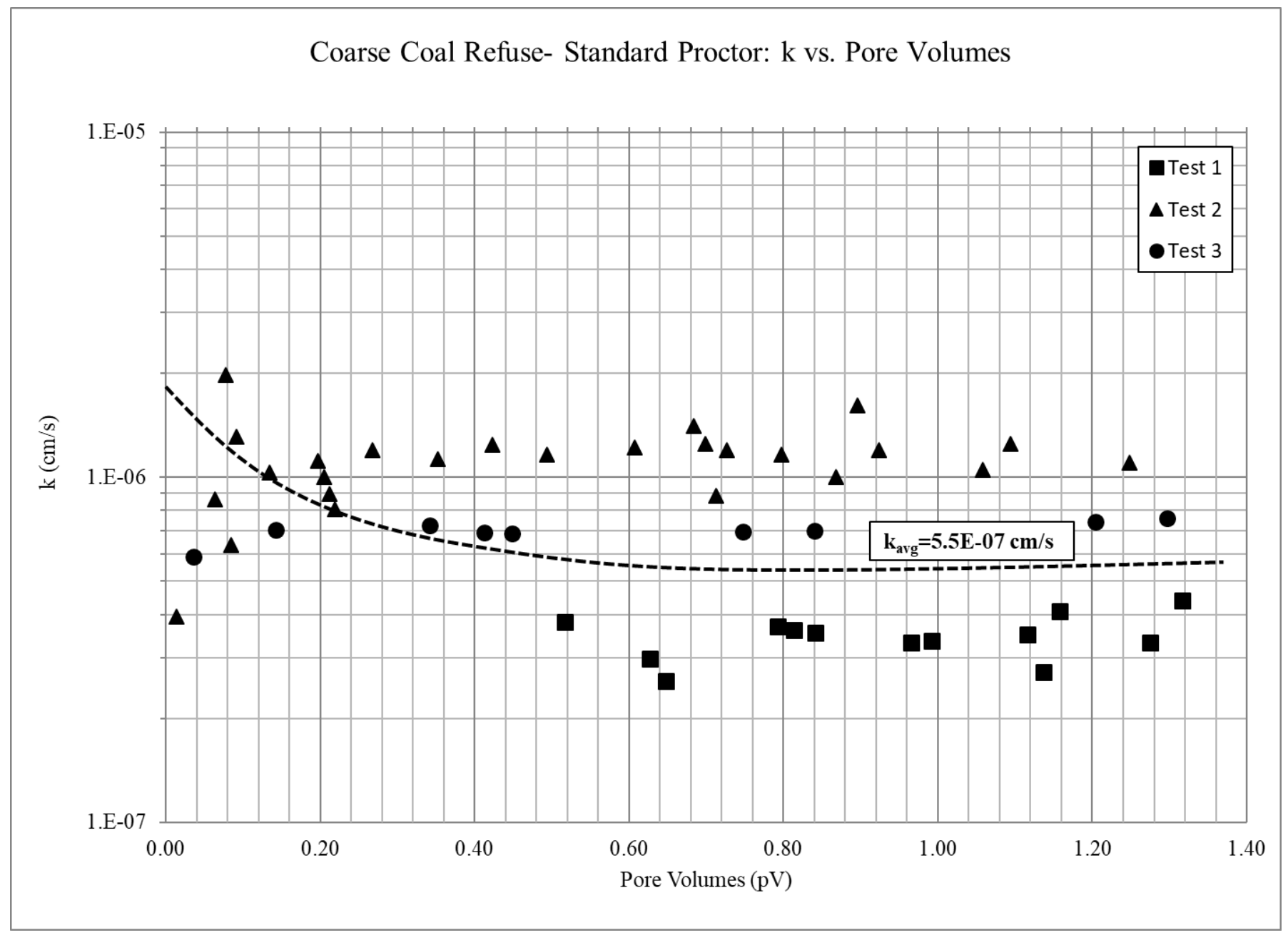

Figure 7. Hydraulic conductivity vs. pore volume plot for standard compacted CCR (592.5 $k J / m^{3}$

\section{$11 \%$ Proctor $80 \% / 20 \%$ CCR/MGro ${ }^{\mathrm{TM}}$ Growth Blend $\left(67.85 \mathrm{~kJ} / \mathrm{m}^{3}\right)$}

Three tests were prepared at $11 \%$ Proctor for hydraulic conductivity testing. The specimens were made up of $80 \% \mathrm{CCR}$ and $20 \% \mathrm{MGro}^{\mathrm{TM}}$ for growth. The tests were targeted to reach a density of $11.2 \mathrm{kN} / \mathrm{m}^{3}$ at $31.9 \%$ moisture content. The data for the testing can be seen in Table 8 below.

The hydraulic conductivity was in the magnitude of $10^{-4} \mathrm{~cm} / \mathrm{s}$ which is fast, but the blend is supposed to allow water to permeate to ensure plant growth. The water contents did not meet the specific $31.9 \%$ moisture content range. This is due to the $\mathrm{MGro}^{\mathrm{TM}}$ material which has an ability to maintain a large volume of water and leads to large standard deviation of water content for each $80 / 20$ blend. Sometimes a large amount of MGro $^{\mathrm{TM}}$ could be in a moisture tin, or a small amount. Large amounts of $\mathrm{MGro}^{\mathrm{TM}}$ naturally leads to high moisture contents, while small amounts lead to low moisture content. The specimens still reach the target density or within 0.5 $\mathrm{kN} / \mathrm{m}^{3}$. 
Table 8. Hydraulic Conductivity results for $11 \%$ Proctor $80 \% / 20 \%$ CCR/MGro ${ }^{T M}$ blend $(67.85$ $\left.\mathrm{kJ} / \mathrm{m}^{3}\right)$

\begin{tabular}{|c|c|c|c|c|c|c|}
\hline Test & $\begin{array}{c}\text { Water } \\
\text { Content } \\
(\boldsymbol{\%})\end{array}$ & $\begin{array}{c}\text { Dry Unit } \\
\text { Weight } \\
(\mathbf{k N} / \mathbf{m 3})\end{array}$ & $\begin{array}{c}\text { Degree of } \\
\text { Saturation } \\
(\mathbf{S})\end{array}$ & $\begin{array}{c}\text { Hydraulic } \\
\text { Porosity } \\
(\mathbf{n})\end{array}$ & $\begin{array}{c}\text { Coefficient of } \\
\text { Conductivity } \\
\text { Average (Last 5 } \\
\text { Points) }(\mathbf{c m} / \mathbf{s})\end{array}$ & $\begin{array}{c}\text { Variation } \\
\text { (Last 5 points) } \\
(\mathbf{c m} / \mathbf{s})\end{array}$ \\
\hline 1 & 21.83 & 11.7 & $57 \%$ & 0.40 & $5.98 \times 10^{-4}$ & 0.8913 \\
\hline 2 & 19.18 & 11.2 & $69 \%$ & 0.43 & $4.05 \times 10^{-4}$ & 0.2938 \\
\hline 3 & 25.55 & 11.5 & $62 \%$ & 0.41 & $1.12 \times 10^{-4}$ & 1.1830 \\
\hline
\end{tabular}

The hydraulic conductivity is plotted against the pore volume for the three tests as well. It was maintained that the specimens reach at least one pore volume to reach a stable filter condition. The plot can be seen in Figure 8. The plot shows that all tests were run over more than one pore volume. This is due to the $\mathrm{MGro}^{\mathrm{TM}}$ material again. As mentioned, it holds in large volumes of water and has an ability to absorb water under a free swell condition, which can lead to large fluctuations in the permeability of the specimens. The plot shows more variability than the standard compacted tests shown in Figure 7. The coefficient of variation is also much higher as compared to the standard compacted specimens. This was expected with a material that takes in large amounts of water. The hydraulic conductivity for the three tests all are close in magnitude as shown in Table 8 , in which all are in the order of $10^{-4} \mathrm{~cm} / \mathrm{s}$. It is believed that the tests reached stable filter conditions even with very high coefficient of variation for each test. 


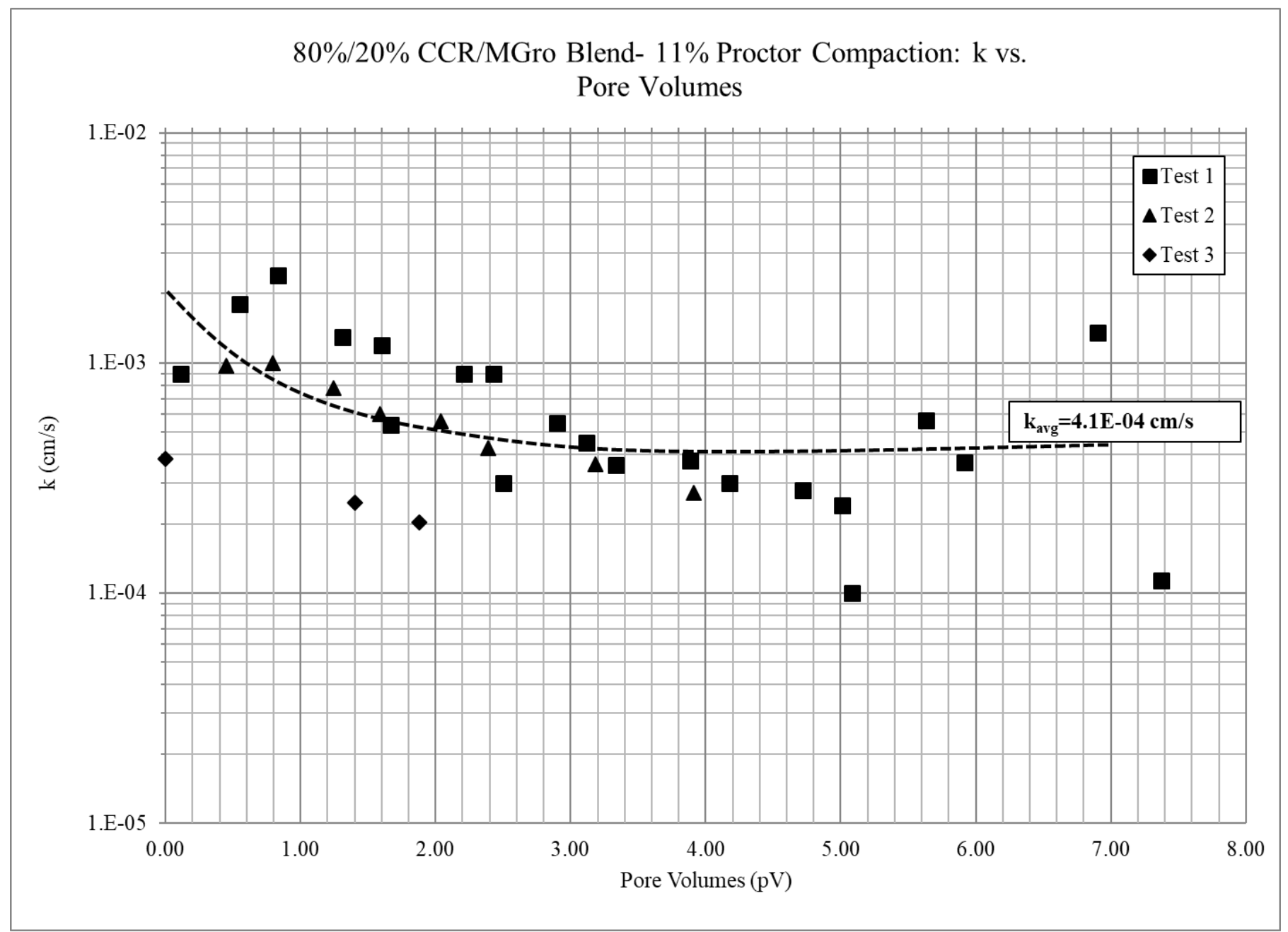

Figure 8. Hydraulic conductivity vs. pore volumes for $11 \%$ compacted $80 \% / 20 \%$ CCR/MGro ${ }^{\text {TM }}$ blend $\left(67.85 \mathrm{~kJ} / \mathrm{m}^{3}\right)$ 


\section{Triaxial Compression Strength Testing Standard Compacted CCR $\left(592.5 \mathrm{~kJ} / \mathrm{m}^{3}\right)$-Total Stress Analysis}

To determine when the material failed, the $p-q$ plot must be analyzed according to a total stress analysis. The p-q plot can be seen in Figure 9. Failure on a $p-q$ plot occurs when the curve changes from left to right at the large bend in each data series. This means when the bow in the curve changes from negative to positive. This large bend is the peak in stress difference for each curve. This can be specified on each plot by the white and black stars for each curve (CCR 1 through 4). Using the data from specified points where the stars are located, the strain rate at which the material fails can be defined in the stress-strain plot in Figure 10.

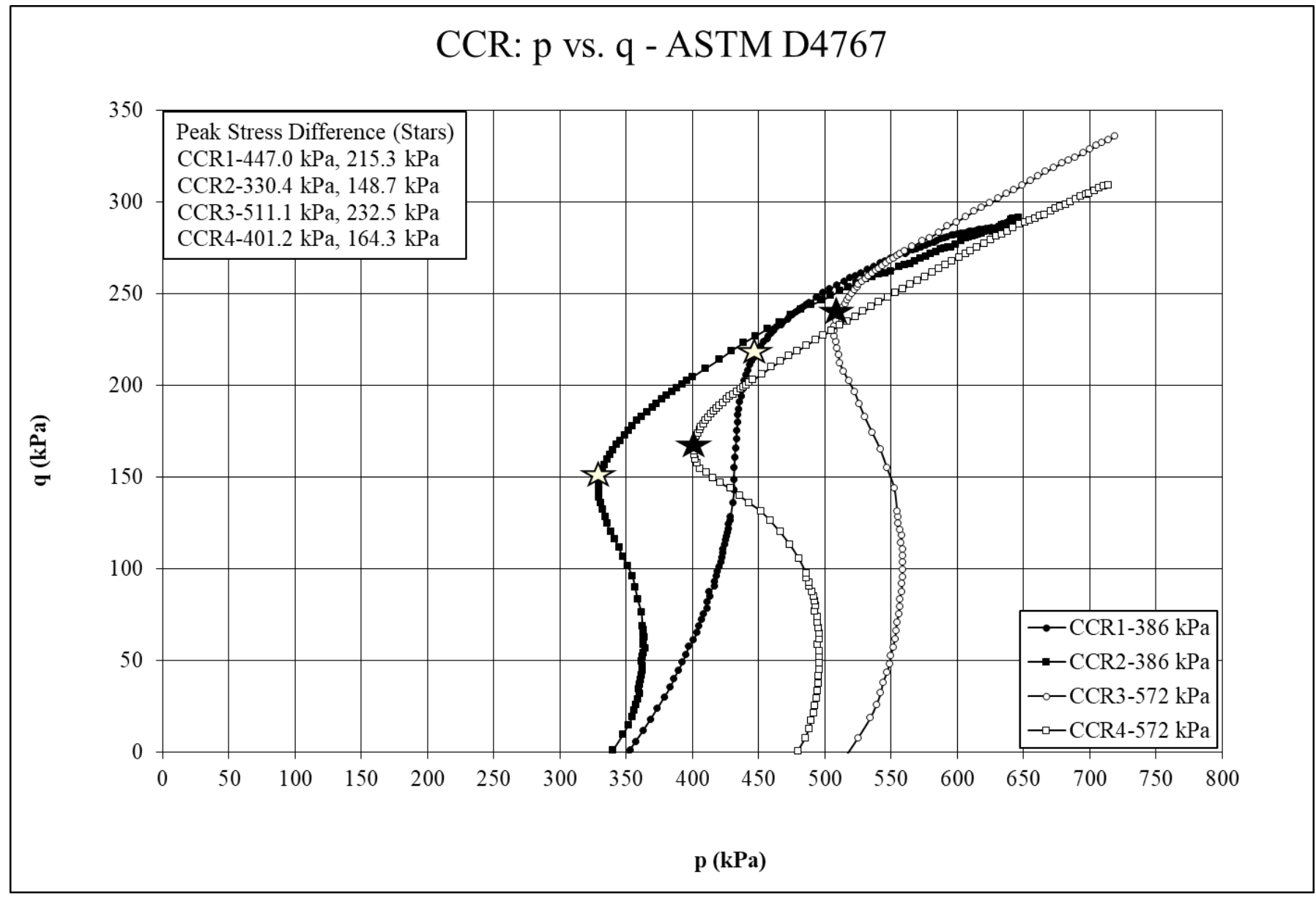

Figure 9. p-q plot for standard compacted CCR $\left(592.5 \mathrm{~kJ} / \mathrm{m}^{3}\right)$

Upon inspection of Figure 10, it can be inferred that there is no residual strength in each of the data series at different confining stresses. Each curve starts with some linear behavior before becoming curvilinear and continuing until around $20 \%$ strain. Without having a peak and a large reduction in shear stress that is prevalent in most stress-strain plots, the $p-q$ plots were vital to determine at what percent strain the material failed at as mentioned in the above paragraph. 
Using the corresponding stress where the stars are placed, the strain rate could be found by matching it to the stress-strain curve seen in Figure 10. The failure points are marked by white and black stars on the stress-strain plot.

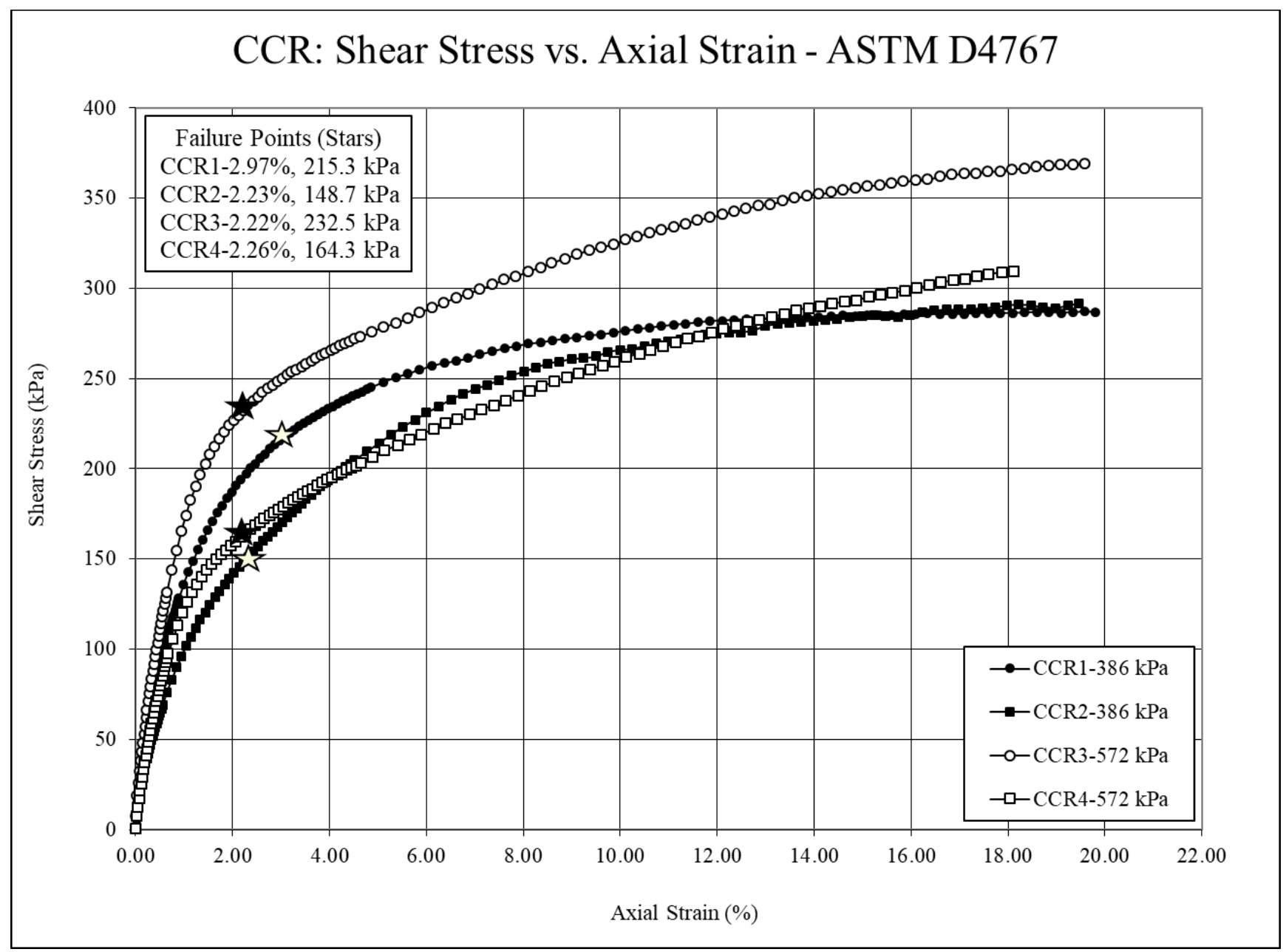

Figure 10. Stress-Strain plot for standard compacted CCR $\left(592.5 \mathrm{~kJ} / \mathrm{m}^{3}\right)$

As can be seen in the plot, the four materials failed between $2.22 \%$ to $2.97 \%$ strain. This shows that the materials had similar behavior at the two different confining pressures. To calculate the internal angle of friction, the maximum $\mathrm{p}$ and $\mathrm{q}$ values for each curve were analyzed. Due to assuming zero cohesion, equations 5 and 6 can be used to get an individual friction angle for each curve. Equations 5 and 6 are taken from the USACE Manual No. 1110-2-1902 (2003).

$\alpha=\tan ^{-1} \frac{q_{\max }}{p_{\max }}$

(Equation 5) 
Table 9. Consolidated Undrained friction angle results for standard compacted CCR (592.5 $\left.k J / m^{3}\right)$

\begin{tabular}{|c|c|}
\hline Tests & $\begin{array}{c}\text { Internal Angle of Friction } \\
\text { (degrees) }\end{array}$ \\
\hline CCR1-386 kPa & 24.89 \\
\hline CCR2-386 kPa & 25.08 \\
\hline CCR3-572 $\mathrm{kPa}$ & 24.78 \\
\hline CCR4-572 kPa & 24.12 \\
\hline
\end{tabular}

Table 10. Summary statistics for friction angle results (standard compacted CCR) (592.5 $\left.k J / m^{3}\right)$

\begin{tabular}{|c|c|}
\hline \multicolumn{2}{|c|}{$\begin{array}{c}\text { Summary Statistics for Standard } \\
\text { Compacted CCR }\end{array}$} \\
\hline Average & 24.72 \\
\hline $\begin{array}{c}\text { Standard } \\
\text { Deviation }\end{array}$ & 0.417 \\
\hline $\begin{array}{c}\text { Coefficient of } \\
\text { Variation }\end{array}$ & 0.0169 \\
\hline
\end{tabular}

The results in Tables 9 and 10 shows that the results from the $\mathrm{CU}$ were accurate and ranged from 24.12-25.08 degrees with an average of 24.72 degrees. The coefficient of variation for these results are low for a small sample size. The average is close to a 2:1 slope (26.6 degrees), which is good in terms of stability.

\section{1\% Compacted 80/20 CCR/MGro ${ }^{\mathrm{TM}}$ blend-Total Stress Analysis}

A total stress analysis was also done on the $80 / 20$ replicants to gain friction angle and determine where failure occurred. $P-q$ plots were generated for analysis, but the results in Figure 11 do not exhibit the curvilinear negative to positive that determined failure for the standard compacted CCR. 80/20-1 shows that the path presented horizontal behavior going back and forth. 80/20-2 had very low values on the q-axis, and had large skewed data fluctuations. 80/20-3 presented completely linear behavior from $0-21.2 \mathrm{kPa}$ on the q-axis, and $50.6-90.1 \mathrm{kPa}$ on the p-axis. 80/20-4 showed some linear behavior before reversing its trend in the opposite direction. The reversing means that the material goes into compression or failure. 


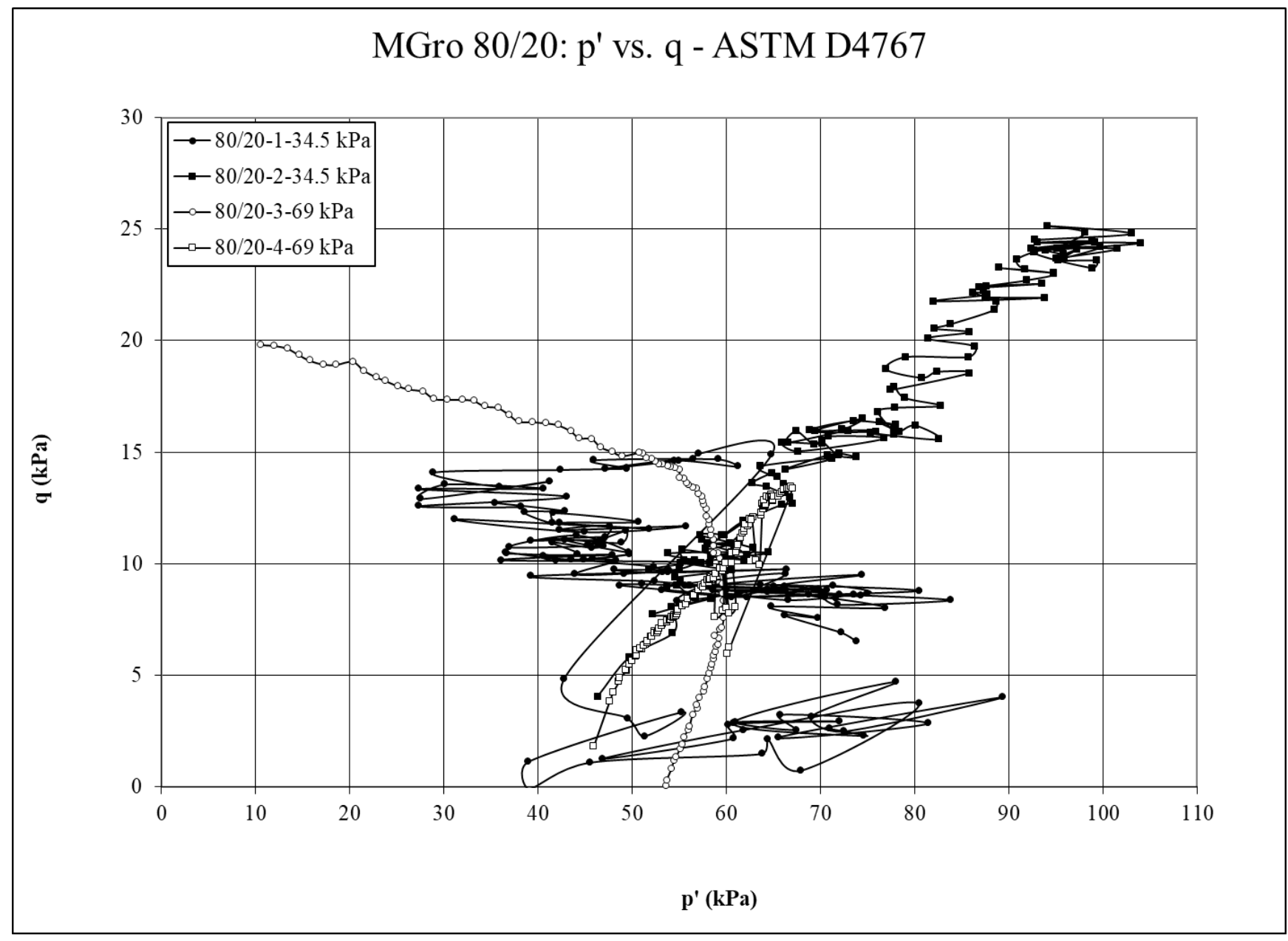

Figure 11. p-q plot for $11 \%$ compacted $80 / 20$ CCR/MGro ${ }^{T M}$ blends $\left(67.85 \mathrm{~kJ} / \mathrm{m}^{3}\right.$

The reason for the behavior can be attributed to the very low compaction effort that was applied to the specimens, and the way MGro ${ }^{\mathrm{TM}}$ behaves naturally. With constant cell-pressure the axial piston applies a compressive stress to the specimen. With a light compaction effort, and MGro ${ }^{\mathrm{TM}}$ making up $20 \%$ of the specimen; the specimen went under a compression behavior like a sponge due to the large amounts of water present in $\mathrm{MGro}^{\mathrm{TM}}$. This could cause the specimens to deform rapidly and give data that is present in Figure 11.

To identify when the material failed, a different approach was taken. The $p-q$ plots show a back and forth behavior, which means the specimens failed at a very low strain. To see how low of a strain, the Mohr-Coulomb stress-strain plot was analyzed, since failure cannot be determined from the p-q plots. Referring to Figure 12, the materials show little to no residual strength. This is a verification of a constant strain failure. Upon inspection of Figure 12, the failure points can be verified. 80/20-1 and 80/20-2 fails at less than $1 \%$ strain. Both replications start an increase and decreasing trend early in their respective curves. This increase/decrease is indicative of failure, and both continue with constant strain to $20 \%$ except for $80 / 20-2$ having a $10 \mathrm{kPa}$ 
decrease in stress. These blends are also the lower of the two confining pressures. 80/20-3 and 80/20-4 fails at less than $4 \%$ strain at a higher confining pressure. Blend 3 fails early in the test by a small decrease in stress, while $80 / 20-4$ has a $1.95 \mathrm{kPa}$ decrease in stress indicating failure. 80/20-4 continues the decreasing trend before continuing constant strain through $20 \%$.

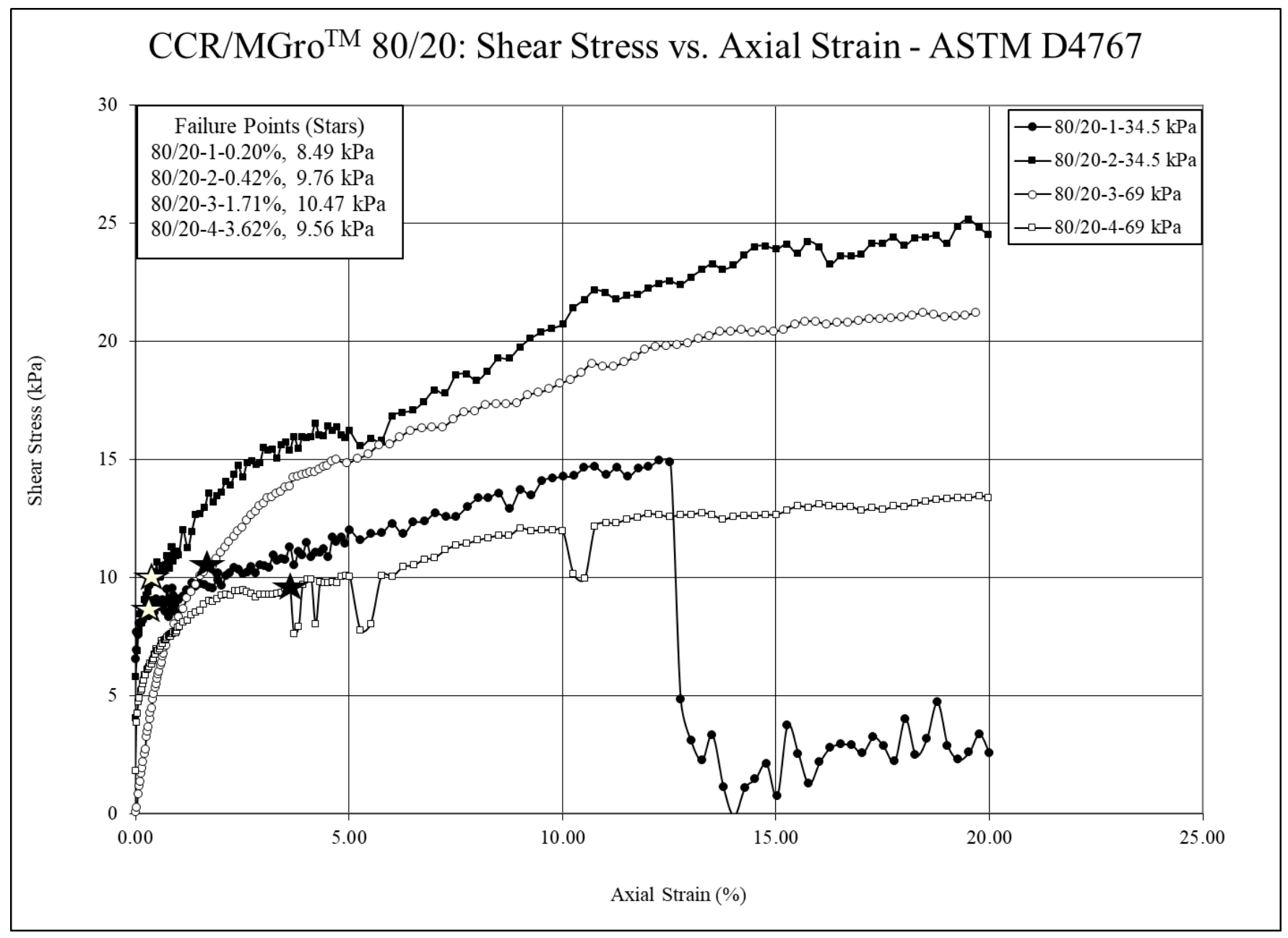

Figure 12. Stress-Strain plot for 11\% Compacted 80\%/20\% CCR/MGro ${ }^{T M}$ blend $\left(67.85 \mathrm{~kJ} / \mathrm{m}^{3}\right)$

Figure 12 indicates that the blends reached peak strength (failed) and continued constant strain behavior. The plots have some similarities in behaviors besides the large decreases in stress for each confining pressure. These large drops can be attributed to the low compaction effort, and $\mathrm{MGro}^{\mathrm{TM}}$ material as the axial load was applied. The next step was to calculate the internal angle of friction for the blend material. Equations 5 and 6 were used to calculate the internal angle of friction using the maximum $p$ and $q$ values gained from testing. The assumption of zero cohesion was also applied for this sweep of testing similar to the standard compacted CCR. 
Table 11. Consolidated Undrained friction angle results for 11\% Compacted 80\%/20\%

CCR/MGro ${ }^{T M}$ blends $\left(67.85 \mathrm{~kJ} / \mathrm{m}^{3}\right)$

\begin{tabular}{|c|c|}
\hline \multicolumn{1}{|c|}{ Tests } & $\begin{array}{c}\text { Internal Angle of Friction (degrees) } \\
\text { (degrees) }\end{array}$ \\
\hline Blend1-34.5 kPa & 10.60 \\
\hline Blend2-34.5 kPa & 16.67 \\
\hline Blend3-69.0 kPa & 13.37 \\
\hline Blend4-69.0 kPa & 12.30 \\
\hline
\end{tabular}

Table 12. Summary statistics for friction angle results (11\% Compacted $80 \% / 20 \%$ CCR/MGro ${ }^{T M}$ blends) $\left(67.85 \mathrm{~kJ} / \mathrm{m}^{3}\right)$

\begin{tabular}{|c|c|}
\hline \multicolumn{2}{|c|}{$\begin{array}{c}\text { Summary Statistics for 11\% } \\
\text { Compacted 80/20 Replications }\end{array}$} \\
\hline Average & 13.24 \\
\hline $\begin{array}{c}\text { Standard } \\
\text { Deviation }\end{array}$ & 2.558 \\
\hline $\begin{array}{c}\text { Coefficient of } \\
\text { Variation }\end{array}$ & 0.1933 \\
\hline
\end{tabular}

Tables 11 and 12 shows that the friction angles ranged from 10.60-16.67 degrees with an average of 13.24. This is wide range for friction angles, but this is expected from a material that has very low density. This material will also serve as the top layer (cover) and is only one foot in thickness. This very low friction angle can also be explained by $\mathrm{MGro}^{\mathrm{TM}}$. MGro ${ }^{\mathrm{TM}}$ is highly organic, and materials that have a high organic content can produce very low internal angles of friction in the range of 0-10 degrees (Koloski et al. 1989). The results for this testing did not fall in that range, but can serve as a guideline for the low internal angles of friction. The coefficient of variation for the blend testing is also high which is expected with a large range of friction angles.

\section{1\% Compacted 80/20 CCR/MGro ${ }^{\mathrm{TM}}$ blend-Effective Stress Analysis}

An effective stress analysis was also done on an $80 / 20$ replication to see the differences between a total and effective stress path. The confining pressure for this test was at $69 \mathrm{kPa}$ similar to the total stress analysis. The major difference in the effective stress analysis is that it takes into the consideration the subtraction of pore-water pressure from the major and minor principal stresses. Instead a $p-q$ plot, a $p^{\prime}-q^{\prime}$ plot will be used to analyze for failure and friction angle. The $p^{\prime}-q^{\prime}$ plot can be seen in Figure 13 . 


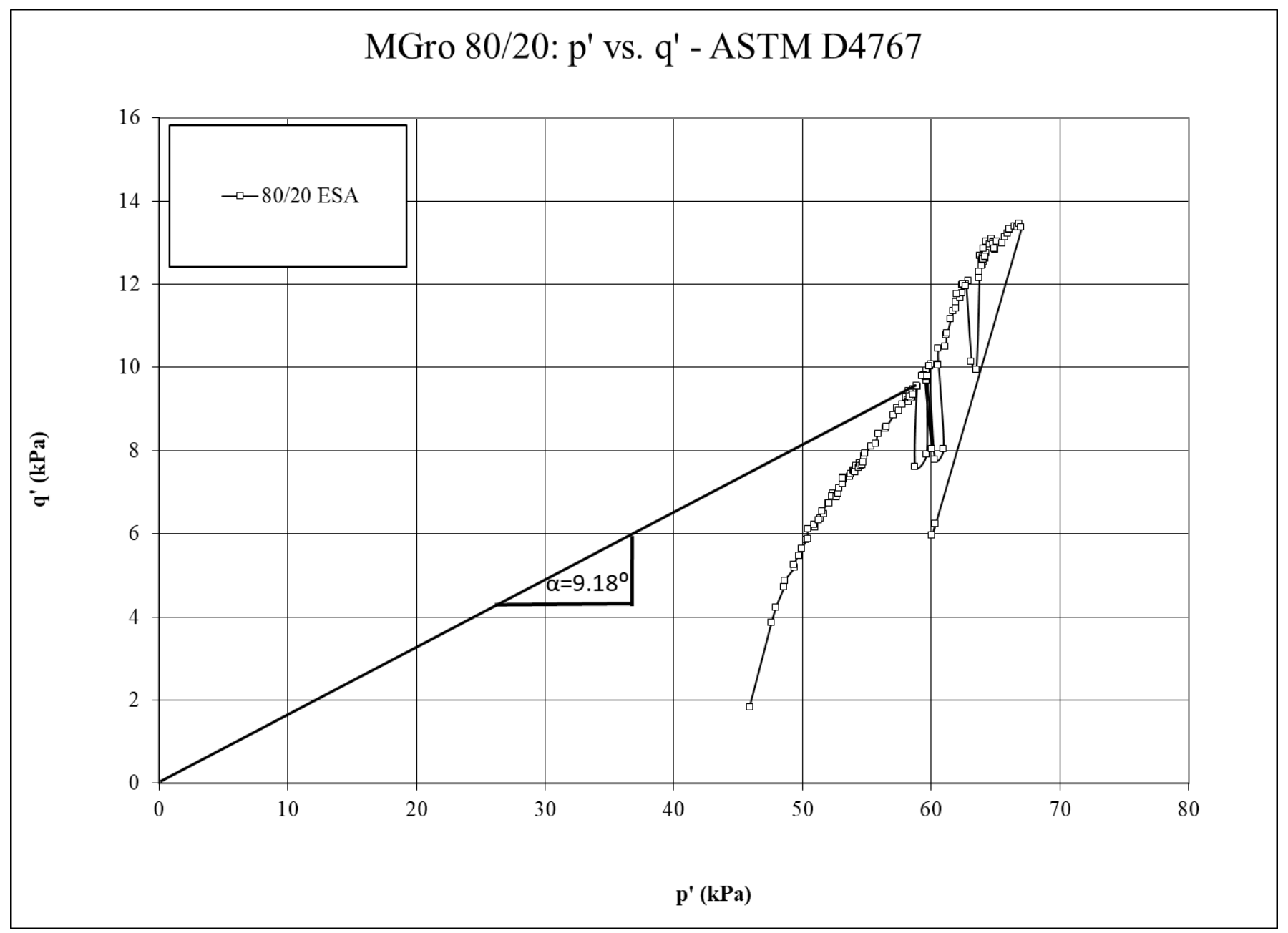

Figure 13. p'-q' plot for 11\% compacted 80/20 CCR/MGro ${ }^{T M}$ blend $\left(67.85 \mathrm{~kJ} / \mathrm{m}^{3}\right)$

The $p^{\prime}-q^{\prime}$ plot shows a much different curve than what was seen in Figure 11. The curve shows that as stress increases up to its failure point at $(58.95 \mathrm{kPa}, 9.54 \mathrm{kPa})$. After that there is a 1.93 decrease in stress at the first large drop. A line of best fit was also used to gain the alpha angle for this set of data. The test was under the assumption of zero cohesion as the line is drawn through the $(0,0)$ axis. The alpha angle was found to 9.18 degrees, and from that point the friction angle could be calculated. Equation 7 shows the calculation of the friction angle based off the alpha angle of the best fit line and was taken from the USACE Manual No. 1110-2-1902 (2003).

$\phi=\arcsin (\tan (\alpha))$

Equation 7 
Table 13. Consolidated Undrained friction angle results for $11 \%$ compacted 80/20 blend $\left(67.85 \mathrm{~kJ} / \mathrm{m}^{3}\right)$

\begin{tabular}{|c|c|}
\hline Tests & $\begin{array}{c}\text { Internal Angle of Friction } \\
\text { (degrees) }\end{array}$ \\
\hline $80 / 20$ Blend-69.0 kPa & 9.30 \\
\hline
\end{tabular}

The friction angle according to the effective stress analysis was 9.30 degrees as seen in Table 13 . This is lower than the four friction angle results from the total stress analysis. The lowest friction angle for the total stress analysis was 10.60 and the highest 16.67. The decrease in friction angle from the effective stress analysis is accredited to the pore-water pressure being subtracted from major and minor principal stresses in the stress-path plot (Figure 13). A pore-pressure-strain plot can be seen in Figure 14 as well. The plot shows that the 80/20 blend went under dilation or an extension of the sample. Most samples when the axial piston is applied go under compression. The extension of the blend is due to the $\mathrm{MGro}^{\mathrm{TM}}$ in the sample is water retentive when it is compressed. It is also noted that first large decrease in in pore-water pressure is at $3.62 \%$ strain, which is what was considered failure for the total stress analysis. 


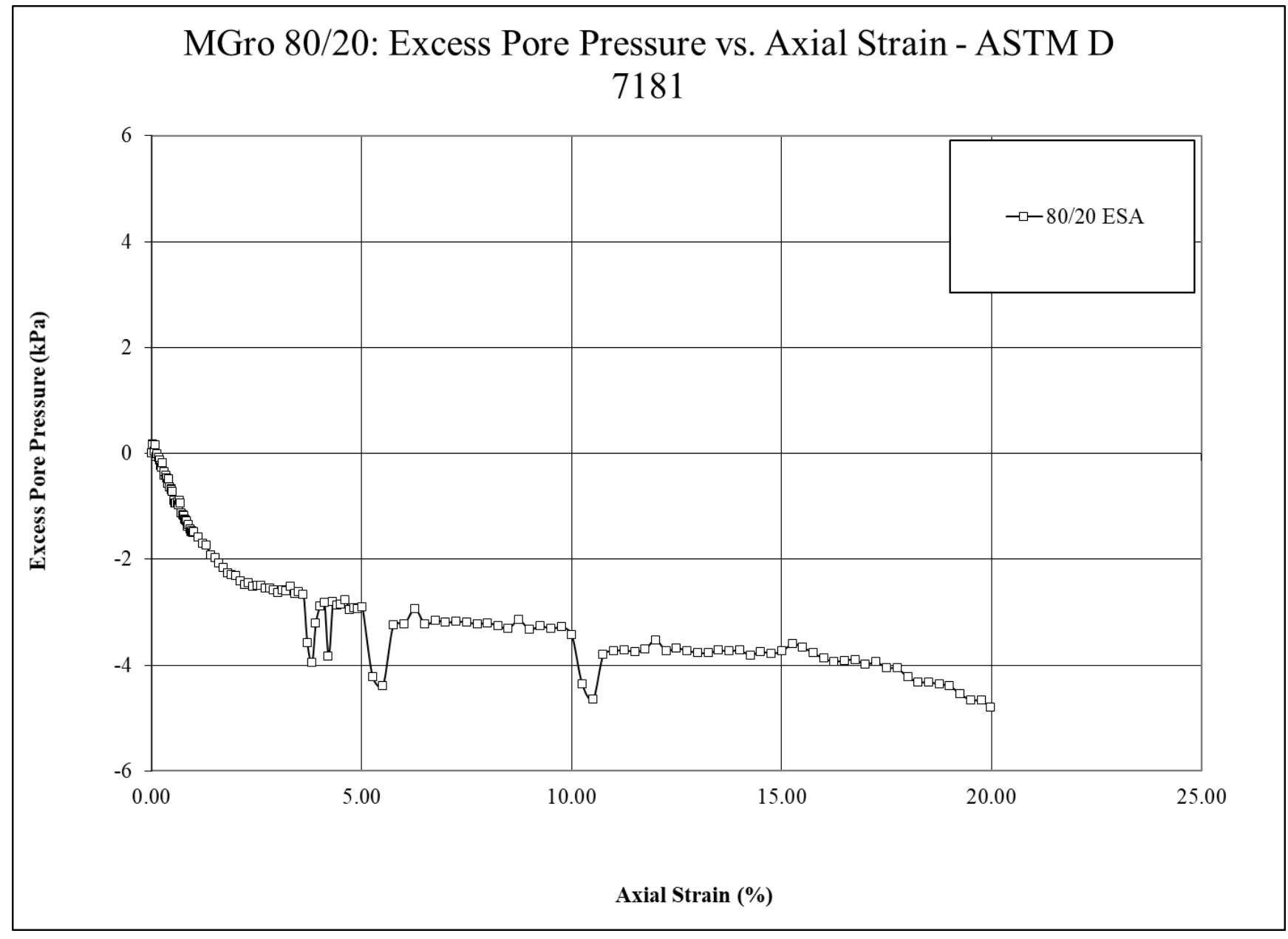

Figure 14. Pore-water pressure versus axial strain for $11 \%$ compacted $80 / 20$ CCR/MGro ${ }^{\text {TM }}$ blend $\left(67.85 \mathrm{~kJ} / \mathrm{m}^{3}\right)$

\section{Summary of Geotechnical Laboratory Testing Results}

Table 14 tabulates the results of geotechnical laboratory testing performed for the Royal Scot site. The research for this study focused on a larger gradation size for CCR, and 80/20 blend testing. A previous researcher did CCR testing and 60/40 blend testing using the same material from their respective sites (Stevens, 2016). There are numerous similarities and differences between this study and the previous researcher's studies that will be discussed in detail.

A full sweep of geotechnical testing was done on the standard compacted CCR $\left(592.5 \mathrm{~kJ} / \mathrm{m}^{3}\right)$ and $11 \%$ compacted $80 / 20 \mathrm{CCR} / \mathrm{MGro}^{\mathrm{TM}}$ blends. Grain size distribution was performed on CCR passing a 19-mm sieve (3/4"), and then compaction, hydraulic conductivity, and triaxial strength testing was performed on the standard compacted CCR, and $11 \%$ compacted blend materials. Research by Stevens (2016) on materials similar to the standard compacted CCR, 11\% compacted blend material, and used a 60/40 CCR/MGro blend. The CCR and MGro ${ }^{\mathrm{TM}}$ materials were taken from the same sites. Table 14 summarizes the material properties tested in this research and lists the corresponding data from Stevens (2016). 
Table 14. Parameter summary table for Geotechnical lab testing

\begin{tabular}{|c|c|c|c|c|c|}
\hline \multicolumn{6}{|c|}{ Royal Scot Laboratory Parameter Summary Table } \\
\hline Geotechnical Property & $\begin{array}{c}\text { CCR Shale } \\
\text { (Stevens, 2016) }\end{array}$ & $\begin{array}{c}\text { MGro }^{\mathrm{TM}} \\
\text { (Stevens, 2016) }^{2}\end{array}$ & $\begin{array}{c}\text { 60/40 CCR- } \\
\text { MGroTM blend } \\
\text { (Stevens, 2016) }\end{array}$ & $\begin{array}{c}\text { 80/20 } \\
\text { CCR/MGro }^{\mathrm{TM}} \\
\text { blend }\end{array}$ & $\begin{array}{c}\text { CCR Passing } \\
19 \mathrm{~mm}\end{array}$ \\
\hline $\begin{array}{l}D_{10} \text { Sand Portion } \\
(\# 4-\# 200)(\mathrm{mm})\end{array}$ & 0.53 & 0.98 & 0.3 & 0.3 & 0.3 \\
\hline $\begin{array}{l}D_{50} \text { Sand Portion } \\
(\# 4-\# 200)(\mathrm{mm})\end{array}$ & 1.72 & 3.35 & 1.7 & 1.6 & 3.0 \\
\hline $\begin{array}{l}\text { \% Passing No. } 200 \text { sieve } \\
\text { (clays and silts) }\end{array}$ & 1.23 & 0.42 & 2.96 & 2.75 & 3.62 \\
\hline Specific Gravity $G_{s}$ & 2.19 & $1.92-2.21$ & - & - & - \\
\hline Plasticity Index, PI & 4 & - & - & - & - \\
\hline$k_{\text {sat }}(\mathbf{c m} / \mathbf{s})$ & $3.50 \mathrm{E}-07-4.22 \mathrm{E}-04$ & - & $8.61 \mathrm{E}-04$ & 3.34E-04 & $6.87 \mathrm{E}-07$ \\
\hline$\varphi^{\prime}$ (degrees) Direct Shear & $41.40-43.80$ & - & 30.16 & - & - \\
\hline$\varphi_{c^{\prime}=0}^{\prime}($ degrees $)$ Direct Shear & $43.21-44.96$ & - & 35.82 & - & - \\
\hline $\mathbf{c}^{\prime}(\mathbf{k P a})$ & $16.99-25.60$ & - & 1.92 & - & - \\
\hline$\varphi_{c^{\prime}=0}^{\prime}($ degrees$) I C U$ & - & - & - & $9.30-16.77$ & $24.12-25.08$ \\
\hline$\gamma_{\text {dmax }}\left(\mathrm{kN} / \mathrm{m}^{3}\right)(200 \%$ Proctor $)$ & 16 & - & - & - & - \\
\hline$\gamma_{\mathrm{d}}\left(\mathrm{lb} / \mathrm{ft}^{3}\right)(200 \%$ Proctor $)$ & 101.9 & - & - & - & - \\
\hline$\omega_{\text {opt }}(\%)(200 \%$ Proctor $)$ & 12.3 & - & - & - & - \\
\hline $\begin{array}{c}\gamma_{\text {dmax }}\left(\mathbf{k N} / \mathbf{m}^{3}\right) \\
\text { (Standard Proctor) }\end{array}$ & 15.9 & - & - & - & - \\
\hline$\gamma_{d}\left(\mathbf{l b} / \mathbf{f t}^{3}\right)($ Standard Proctor) & 88.3 & 50.9 & 74.5 & - & - \\
\hline$\omega_{\text {opt }}(\%)$ (Standard Proctor) & 14.3 & - & - & - & - \\
\hline$\gamma_{90 \%}\left(\mathbf{l b} / \mathbf{f t}^{3}\right)$ & 87.57 & - & 74.08 & - & - \\
\hline$\omega_{90 \%}$ & 12.8 & - & 27.2 & - & - \\
\hline$\gamma_{\text {dmax }}\left(k N / m^{3}\right)(34 \%$ Proctor $)$ & 15.1 & - & - & - & - \\
\hline$\omega_{\text {opt }}(\%)(34 \%$ Proctor $)$ & 17 & - & - & - & - \\
\hline$\gamma_{d \max }\left(\mathrm{kN} / \mathrm{m}^{3}\right)(11 \%$ Proctor $)$ & 14.6 & - & 11.7 & 11.2 & 13.07 \\
\hline$\omega_{\text {opt }}(\%)(11 \%$ Proctor $)$ & 17.5 & - & 28 & 31.9 & 11.8 \\
\hline
\end{tabular}

* Dashes (-) represent lab testing that is not available. *

\section{Observations of CCR geotechnical laboratory testing:}

For the GSD testing, there are some differences with the indices listed in Table 14. As mentioned a larger gradation was used for this study, and was sieved in the field up to $19 \mathrm{~mm}$. Stevens (2016) shows that there are larger diameter particles at the sand portions of $\mathrm{D}_{50}$ and $\mathrm{D}_{10}$. The reason for this is that the testing done for this report was already sieved in the field and put through the GSD procedure. The testing done by Stevens (2016) used in-situ material, which had very large $(50.8 \mathrm{~mm})$ material that sat on top of the \#4 sieve. That is the reason for the smaller values of 1.72 and $0.53 \mathrm{~mm}$ for $\mathrm{D}_{50}$ and $\mathrm{D}_{10}$, as opposed to 3.0 and $0.30 \mathrm{~mm}$. 
The combined GSD can be seen in Figure 5. The percent passing a No. 200 sieve for this study produces more crushed fines in the silt and clay range particles (fines) as opposed to Stevens as well, which is expected with smaller diameter particles (Stevens, 2016). The final comparison for the GSD is that the material for this study classifies as a well graded sand with gravels (SW) as opposed to Stevens' poorly graded sand with gravels (SP). This is due to (Stevens, 2016) having a large $(50.8 \mathrm{~mm})$ shale material that is mentioned above. That large piece of shale changed the coefficient of uniformity, which governs the final classification from well to poorly graded.

Compaction testing was performed on two $11 \%$ Proctor energies, which consisted of CCR, and an $80 / 20$ blend. The $11 \%$ compaction $\left(67.85 \mathrm{~kJ} / \mathrm{m}^{3}\right)$ was used to approximate the refuse at a density approximate to being end-dumped from a loader or similar construction equipment. In comparison, Stevens (2016) had two 11\% compaction specimens, which were CCR and a 60/40 blend. A major difference for the CCR was that for this study, a max $19 \mathrm{~mm}$ gradation was used and Stevens used a max gradation of $4.76 \mathrm{~mm}$ (\#4 sieve), which is four times as large. Table 14 shows that the dry unit weight and moisture content for the larger gradation decreased by 1.53 $\mathrm{kN} / \mathrm{m}^{3}$ and $5.7 \%$ respectively. For a shale material, the larger the particle size, the less water it can hold in, which is in accordance with the results from the laboratory testing. The 80/20 and $60 / 40$ blends show that they both performed very similarly. 80/20 blend had a dry unit weight and moisture content of $11.20 \mathrm{kN} / \mathrm{m}^{3}$ and $31.90 \%$, while $60 / 40$ had $11.70 \mathrm{kN} / \mathrm{m}^{3}$ and $28.00 \%$. Both are very close in density and moisture content, with $60 / 40$ having a $0.5 \mathrm{kN} / \mathrm{m}^{3}$ increase in density with a lower moisture content. This can be explained for either material by inconsistencies with the $\mathrm{MGro}^{\mathrm{TM}}$ material. Any moisture content that is taken to be dried during compaction testing could have a large amount or small amount of $\mathrm{MGro}^{\mathrm{TM}}$. The more $\mathrm{MGro}^{\mathrm{TM}}$; the higher moisture content, and vice-versa.

For the hydraulic conductivity testing, standard compacted CCR $\left(592.5 \mathrm{~kJ} / \mathrm{m}^{3}\right)$ and $11 \%$ compacted $80 / 20$ blend $\left(67.85 \mathrm{~kJ} / \mathrm{m}^{3}\right.$ ) testing will be compared to Stevens testing (Stevens, 2016). Both tested standard compacted CCR, but the research done for this study was done with flexible-wall testing as opposed to rigid-wall testing. Flex-wall was chosen because of the possibility of particle migration in rigid-wall permeability testing. Under standard compacted conditions for CCR, both studies show that the laboratory permeability of two different max gradation had velocities in the magnitude of $10^{-7} \mathrm{~cm} / \mathrm{s}$. For this research, it was expected that the larger $19 \mathrm{~mm}$ gradation, would have a much faster permeability, but that was not the case as both performed similar according to Table 14 . This study had a hydraulic conductivity of $6.87 \times 10^{-7}$ $\mathrm{cm} / \mathrm{s}$, which Stevens posted $3.50 \times 10^{-7} \mathrm{~cm} / \mathrm{s}$. The 80/20 and 60/40 CCR/MGro ${ }^{\text {TM }}$ blends had much lower magnitudes but similar conductivities once again. Both blends were in the magnitude of $10^{-4} \mathrm{~cm} / \mathrm{s}$. The expectation for the $80 / 20$ blend was that it would be in the order of $10^{-3} \mathrm{~cm} / \mathrm{s}$ with a $50 \%$ reduction of $\mathrm{MGro}^{\mathrm{TM}}$, but that was not the case. MGro ${ }^{\mathrm{TM}}$ takes in large amounts of water so it was expected to be able to flow faster through a larger $19 \mathrm{~mm}$ max gradation than with $50 \%$ more $\mathrm{MGro}^{\mathrm{TM}}$ and a smaller $4.76 \mathrm{~mm}$ max gradation. 
The final testing comparison is for the internal angle of friction for standard compacted CCR, and $11 \%$ blends that were tested. First, this study used isotropic triaxial compression ICU testing, while Stevens (2016) used direct shear testing. Reference to Table 14, presents the friction angles under cohesionless conditions show the friction angle results are much higher than the results of the ICU testing. The standard Proctor compacted CCR posted friction angles ranging from 24.12-25.08 degrees, while Stevens (2016) results were 43.21-44.96 degrees. The 80/20 testing had a range of 9.30-16.77, while 60/40 was 35.82 degrees. The lower bound (9.30 degrees) was analyzed using an effective stress analysis, while the upper bounds were calculated using a total stress analysis. This is a very large difference between two similar materials. As mentioned, the maximum gradation size for this study was four times as large as the gradation for Stevens, and there was a $50 \%$ reduction of MGro $^{\mathrm{TM}}$ between $60 / 40$ to $80 / 20$. This does not mean that the gradation/reduction is the direct cause. The main cause for this result is likely due to the change of testing procedure and the behavior of the refuse under the ICU conditions. Typically for direct shear, materials with very small particle size are used. The GSD (Figure 5) results for passing a \#200 sieve in Table 14 show that very little clay/silts were present in the materials (less than $5 \%$ ). During the direct shear test, a larger particle could have been at the threshold of the shear plane. The particles shape and orientation then could force the material to have higher friction angles than expected. 


\section{Numerical Modeling}

To see the effects of the laboratory testing on the Royal Scot site, Finite Element Modeling (FEM) was performed on two separate 2D slopes. The first slope was a conventional planar slope that had geometry close to a 2:1 profile. The other slope was a geomorphic channel. These two slopes performances will be measured using seepage and slope stability analysis. An image of the Royal Scot site with the locations of these slope profiles can be seen in Figure 15. The locations are indicated by the black boxes. The conventional planar slope located near Ditch $\mathrm{G}$ includes one bench that measures 7 feet. The geomorphic slope does not have benches and is less steep.

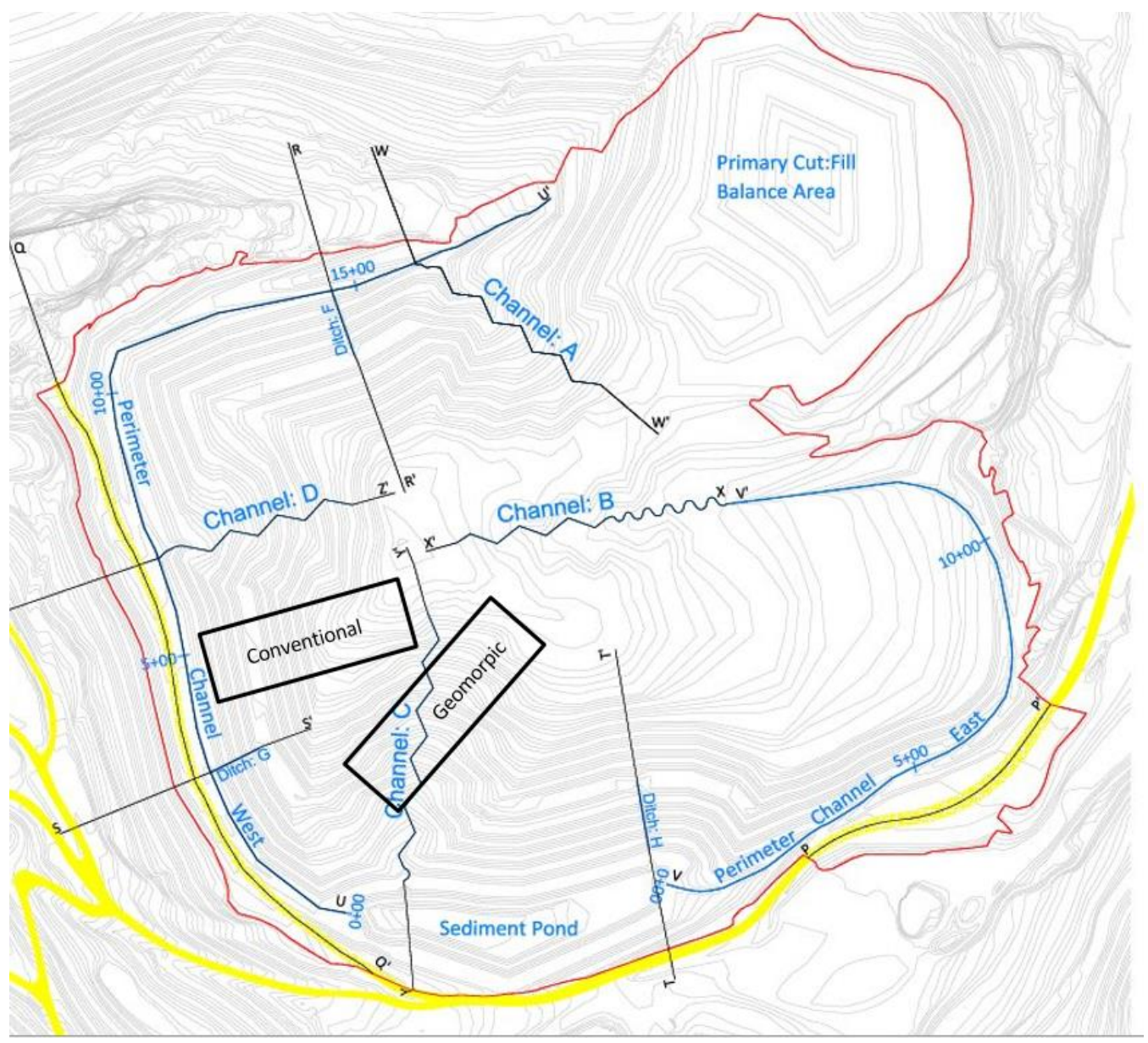

Figure 15. Image of Royal Scot plan including the location of slope profiles that are modeled (Adapted from Lorimer, 2016)

\section{Modeling Methodology}

The modeling for this study was done using SVOffice ${ }^{\mathrm{TM}}$. Within SVOffice ${ }^{\mathrm{TM}}$ there are two programs named SVFlux ${ }^{\mathrm{TM}}$ and SVSlope ${ }^{\circledR}$. SVFlux ${ }^{\mathrm{TM}}$ was be used for the seepage analysis implementing climate into the two slope profiles. SVSlope ${ }^{\circledR}$ was used for slope stability analysis after the seepage analysis has occurred. This allows the slope to be analyzed for stability after the soil has become saturated, simulating a worst-case scenario. These two programs allowed the 
overall performance of the cap and cover system to be evaluated at according to the laboratory testing. The models were also analyzed using unsaturated soil mechanics. This means that the all soil profiles were modeled as an unsaturated condition, until the a 100-year storm occurred.

\section{SVFlux $^{\text {TM }}$}

The two slope profiles were run for 25 days within SVFlux ${ }^{\mathrm{TM}}$. The 25 days is to see how a 100year 24-hour storm infiltration affects the Royal Scot site. The storm was inserted on the first day of the model, and seepage affects were analyzed. The data was gathered from the NOAA Point Precipitation Frequency Estimates. Table 15 list all the details of the storm event.

Table 15. Probabilistic storm data for modeling

\begin{tabular}{|c|c|c|}
\hline Storm Event & Station & Volume (m/day) \\
\hline $\begin{array}{c}\text { 100-year } \\
\text { 24-hour }\end{array}$ & $\begin{array}{c}\text { East Rainelle 3 } \\
\text { NNE }\end{array}$ & 0.135 \\
\hline
\end{tabular}

The station used was close to the Royal Scot Site and was East Rainelle 3 NNE (46-2638) station. The 100 -year storm had a volume of $0.135 \mathrm{~m} /$ day. This storm should allow the growth (cover) layer to completely saturate and see how much water infiltrates into the hydraulic barrier. The storm data could be input into the SVFlux ${ }^{\mathrm{TM}}$ via climate boundary condition. The other boundary condition that was used in SVFlux ${ }^{\mathrm{TM}}$ consisted of review boundaries. A review boundary is used in SVFlux ${ }^{\mathrm{TM}}$ to allow flow into or out of the model depending on differences in pressure. These were used on both models to allow the fluxes to flow into or out of the model. The last condition that was inserted into the model were flux lines. Flux lines are used to track the amount of flux that travels through the line. The flux lines in this model were used to track infiltration from the hydraulic barrier into the fill material. The flux line was drawn from the bench of the conventional planar slope to the toe under the hydraulic barrier layer. The flux line reports infiltration in cubic meters of flow. Since it is a 2-D model, the thickness of the slope is 1-meter so that cubic meters of infiltration is possible. For the geomorphic slope, the line was drawn from lower $66 \%$ of the slope to the toe under the hydraulic barrier. Table 16 shows a list of boundary conditions and their location on the two slope profiles.

Table 16. Boundary condition locations

\begin{tabular}{|c|c|}
\hline Boundary Conditions & Locations \\
\hline Climate Boundary & Top of growth layer \\
\hline Review Boundary & Toe of slopes \\
\hline $\begin{array}{c}\text { Flux Line } \\
\text { (Conventional) }\end{array}$ & Bench to toe \\
\hline $\begin{array}{c}\text { Flux Line } \\
\text { (Geomorphic) }\end{array}$ & Lower $66 \%$ to toe \\
\hline
\end{tabular}




\section{SVSlope ${ }^{\circledR}$}

SVSlope ${ }^{\circledR}$ is the finite element analysis program used for the analysis of slope stability based on the limit equilibrium approach. For this study, the slopes will be analyzed in two dimensions. The program includes several material failure modes including Mohr Coulomb, Hoek-Brown, and several others; for this analysis Mohr-Coulomb will be used. SVSlope ${ }^{\circledR}$ also has several calculation methods for safety factors. Some of these methods include: General Limit Equilibrium (GLE), Bishop's simplified method of slices, Janbu method of slices, and several others. For this analysis, the GLE was chosen because it takes into consideration the inter-slice shear forces. Another useful tool within SVSlope ${ }^{\circledR}$ is the ability to couple with SVFlux ${ }^{\mathrm{TM}}$ for transient analysis with saturation and groundwater data. Coupling the two programs allows the user to see the effects of pore-water pressure and climate on the slope profiles.

\section{Unsaturated Soil Mechanics}

The growth layer will be saturated during a storm event, so the cap part of the system will be modeled as a saturated condition. This will not be the case for the hydraulic barrier and the fill material. The barrier and fill material will be modeled as an unsaturated condition. The barrier is designed to saturate over time due to storms, and allow little to no water to seep into the fill material.

Therefore, unsaturated hydraulic conductivity calculations were required for these cover systems. The unsaturated soil properties were done using the Fredlund and Xing equation for the SoilWater Characteristic Curve (SWCC) (Lu and Likos 2004). The equation can be seen below in Equation 8.

$$
\theta(\psi)=\left(1-\frac{\ln \left(1+\frac{\psi}{\psi_{r}}\right)}{\ln \left(1+\frac{100000}{\psi_{r}}\right)}\right) \theta_{s}\left(\frac{1}{\left(\ln \left[e+\left(\frac{\psi}{a}\right)^{n}\right]\right)^{m}}\right)
$$

where,

$\theta=$ volumetric water content $(\%)$

$\psi=$ matric suction $(\mathrm{kPa})$

$\psi_{r}=$ matric suction corresponding to residual water content $=\mathrm{h}_{\mathrm{r}}(\mathrm{kPa})$

$\theta_{s}=$ saturated volumetric water content (\%)

$a$ : curve fitting parameter

$n$ : curve fitting parameter

$m$ : curve fitting parameter

$h_{r}$ : curve fitting parameter 
There was one issue with the curve fitting parameters: $\mathrm{a}, \mathrm{n}, \mathrm{m}$, and $\mathrm{h}_{\mathrm{r}}$. The parameters are based on $\mathrm{D}_{10}$ from the grain size distribution and gave results that were not justifiable. It was then discovered the Torres (2011) equation could be used for large coarse materials. The $\mathrm{D}_{10}$ of 0.28 mm from Table 4 was not able to fit the Torres' equations so a maximum value of $\mathrm{D}_{10}$ equal to 0.11 was used for the SWCC. The fitting parameters for the Torres Equation can be seen below.

$$
\begin{array}{lr}
a_{f}=-967.21\left(D_{10}^{2}\right)+218.37\left(D_{10}\right)-2.7 & \text { (Equation 9) } \\
n=10^{\left(-0.0075 a_{f}^{3}+0.1133 a_{f}^{2}-0.3577 a_{f}+0.3061\right)} & \text { (Equation 10) } \\
m=0.0058 a_{f}^{3}-0.0933 a_{f}^{2}+0.4069 a_{f}+0.3481 & \text { (Equation 11) } \\
h_{r}=100 & \text { (Equation 12) }
\end{array}
$$

\section{Table 17. Soil Water Characteristic Curve (SWCC) Parameters}

\begin{tabular}{|c|c|}
\hline Soil Water Characteristic Curve & Parameter \\
\hline $\mathrm{a}_{\mathrm{f}}$ & 9.62 \\
\hline $\mathrm{n}$ & 4.72 \\
\hline $\mathrm{m}$ & 0.79 \\
\hline $\mathrm{h}_{\mathrm{r}}$ & 100 \\
\hline
\end{tabular}

\section{Modeling Inputs}

For SVFlux ${ }^{\mathrm{TM}}$ and SVSlope ${ }^{\circledR}$ to give accurate results, input parameters from geotechnical laboratory testing were used. For SVFlux ${ }^{\mathrm{TM}}$ properties include hydraulic conductivity, volumetric water content, and Soil-Water Characteristic Curve variables are used. SVSlope ${ }^{\circledR}$ uses failure mode parameters. Since Mohr-Coulomb is used for this analysis, input parameters include: dry unit weight, cohesion, and internal angle of friction.

\section{SVFlux ${ }^{\mathrm{TM}}$ Input Parameters}

The input parameters for SVFlux ${ }^{\mathrm{TM}}$ consist of saturated hydraulic conductivity and volumetric water content (porosity $(\mathrm{n})$ ), and specific gravity $\left(\mathrm{G}_{\mathrm{s}}\right)$. Aside from these two parameters, the soilwater characteristic curve includes data that corrects the hydraulic conductivity for an unsaturated scenario. The data that was used are the Equations 9 through 12 (Torres, 2011). The equations are related to $\mathrm{D}_{10}$ of CCR shale. Figure 5 shows a compilation of the GSD curves. The original results for $\mathrm{D}_{10}(0.30 \mathrm{~mm})$ of the CCR shale gave undesirable results for the fitting parameters. A $D_{10}$ value of $0.11 \mathrm{~mm}$ was used as the maximum for the fitting parameters according to the Torres equation. The $\mathrm{D}_{10}$ particle size yielded fitting parameters of $\mathrm{a}_{\mathrm{f}}=9.62$, $\mathrm{n}_{\mathrm{f}}=4.72, \mathrm{~m}_{\mathrm{f}}=0.79$, and $\mathrm{h}_{\mathrm{r}}=100$. Parameter af governs the approximate air entry value, $\mathrm{n}_{\mathrm{f}}$ controls 
the slope of the curve at its inflection point, $\mathrm{m}_{\mathrm{f}}$ is related to the residual water content, and $\mathrm{h}_{\mathrm{r}}$ correlates to matric suction under residual water conditions (DePriest, 2015). The input parameters for SVFlux ${ }^{\mathrm{TM}}$ are presented in Table 18.

Table 18. SVFlux ${ }^{T M}$ input parameters for modeling

\begin{tabular}{|c|c|c|c|}
\hline \multicolumn{4}{|c|}{ SVFlux $^{\text {TM }}$ Input Parameters } \\
\hline Input Parameters & $\mathbf{8 0 / 2 0}$ Blend & $\begin{array}{c}\text { Hydraulic } \\
\text { Barrier }\end{array}$ & Fill CCR \\
\hline $\mathrm{k}_{\text {sat }}$ (m/day) & 0.289 & 0.0594 & 0.3456 \\
\hline $\begin{array}{c}\text { volumetric water } \\
\text { content (n) }\end{array}$ & 0.48 & 0.35 & 0.45 \\
\hline $\mathrm{G}_{\mathrm{s}}$ & 2.00 & 2.19 & 2.65 \\
\hline
\end{tabular}

\section{SVSlope ${ }^{\circledR}$ Input Parameters}

As mentioned, dry unit weight, cohesion, and friction angle are the major input parameters for SVSlope ${ }^{\circledR}$. The dry unit weight and cohesion stayed constant on both slope profiles, and were not changed. Dry unit weight takes the water content into consideration. For the internal angle of friction, a sensitivity analysis was performed according to the Three-Sigma rule for small sample sizes to account for uncertainty in the hydraulic barrier and 80/20 growth layer. According to Duncan (2000), the Three-Sigma Rule uses the fact that $99.73 \%$ of all values of a normally distributed parameter fall within three standard deviations of the average. The Three-Sigma rule can be used to estimate a value of standard deviation by first obtaining highest and lowest conceivable values of the parameter. Equation 13 shows the equation for the estimated standard deviation (Duncan, 200)

$\sigma_{3}=\frac{H C V-L C V}{6}$

$\mathrm{HCV}=$ highest conceivable value

$\mathrm{LCV}=$ lowest conceivable value

Table 19. 3-Sigma friction angle values

\begin{tabular}{|l|c|c|c|}
\hline Hydraulic Barrier & LCV & Mean & HCV \\
\hline Friction Angle (degrees) & 24.24 & 24.72 & 25.20 \\
\hline Standard Deviation (degrees) & \multicolumn{3}{|c|}{0.16} \\
\hline 80/20 Growth Layer & LCV & Mean & HCV \\
\hline Friction Angle (degrees) & 10.22 & 13.22 & 16.22 \\
\hline Standard Deviation (degrees) & \multicolumn{4}{|c|}{1.0} \\
\hline
\end{tabular}


Three friction angle values for the hydraulic barrier and 80/20 growth layer were chosen for the two slope profiles according to the sensitivity analysis. The values are listed in Table 19. The highest conceivable (HCV), mean, and lowest conceivable (LCV) values were all run in SVSlope ${ }^{\circledR}$ to establish a parametric range of safety factors. The rest of the input parameters are presented in Table 20. The commas for the friction angle values is the different angles that were chosen based off the Three-Sigma analysis, that were listed in Table 19. All parameters used for the slope stability analysis were laboratory tested apart from the inputs that have an asterisk $(*)$ next to them. These were recommended to use for the fill material, since laboratory testing had not been done on that material (Stevens, 2016). The c' (cohesion) has very low values due to the inherent nature of the refuse. In the laboratory testing, zero-cohesion assumptions were used since the material was shale, and produces a small number of fines. The model is not able to run with zero inputted for cohesion, so very small values were used for each layer.

Table 20. SVSlope ${ }^{\circledR}$ input parameters for modeling

\begin{tabular}{|c|c|c|c|}
\hline \multicolumn{4}{|c|}{ SVSlope ${ }^{\circ}$ Input Parameters } \\
\hline Input Parameters & $\mathbf{8 0 / 2 0}$ Blend & Hydraulic Barrier & Fill CCR \\
\hline$\varphi\left({ }^{\circ}\right)$ & $10.22,13.22,16.22$ & $24.24,24.72,25.20$ & $40.54^{*}$ \\
\hline $\mathrm{c}^{\prime}(\mathrm{kPa})$ & 1.00 & 2.00 & 2.00 \\
\hline$\gamma\left(\mathrm{kN} / \mathrm{m}^{3}\right)$ & 11.20 & 15.90 & $18.02^{*}$ \\
\hline
\end{tabular}

* signifies parameters done by Stevens, 2016

\section{Modeling Results}

Using the input parameters for SVFlux ${ }^{\mathrm{TM}}$ and SVSlope ${ }^{\circledR}$, the conventional planar slope and geomorphic could be analyzed for seepage and stability. Both conventional and geomorphic slopes had a 0.6-meter ( $2 \mathrm{ft}$ ) hydraulic barrier and 0.3-meter ( $1 \mathrm{ft}$ ) 80/20 growth layer. The only difference was the conventional planar slope had a 0.6-meter barrier through the benched area, and was then tapered to 0.3 meters on the downslope toward the toe of the slope. This taper was to reduce pore pressure build-up that happens in conventional planar slopes toward the toe due to a saturated hydraulic barrier. For the hydrologic output, both slope profiles were analyzed for precipitation and infiltration from the hydraulic barrier into fill material. The growth layer is designed to experience a large amount of infiltration due to its light compaction effort. This also allows excess water to ensure plant growth.

The models simulated the effects of a 100 -year 24 -hour storm event $(0.135 \mathrm{~m} /$ day or $135 \mathrm{~mm}$ of rainfall). The slopes were modeled to be in a partially saturated state, and the storm event occurred on day 1 of 25 successive days. The 25-day duration allows the movement of infiltration and saturation of the slope after a 100-year storm has occurred. Slope stability calculations were done after the storm event has occurred to get a worst-case scenario on the lowest factor of safety for the conventional planar and geomorphic slopes. 


\section{Conventional Planar Slope (Ditch G) Saturation and Streamlines}

Figures 16 to 19 show the saturation of the conventional planar slope before and after the storm event. Table 21 helps to identify the saturation on each corresponding day.

Table 21. Saturation of growth layer and hydraulic barrier

\begin{tabular}{|c|c|c|}
\hline \multicolumn{3}{|c|}{ Conventional Planar Ditch G } \\
\hline Day & Growth Layer Saturation (\%) & Hydraulic Barrier Saturation (\%) \\
\hline 3 & 100 & 40 to 50 \\
\hline 4 & 100 & 50 \\
\hline 15 & 100 & 20 to 30 \\
\hline 25 & 100 & 15 to 20 \\
\hline
\end{tabular}

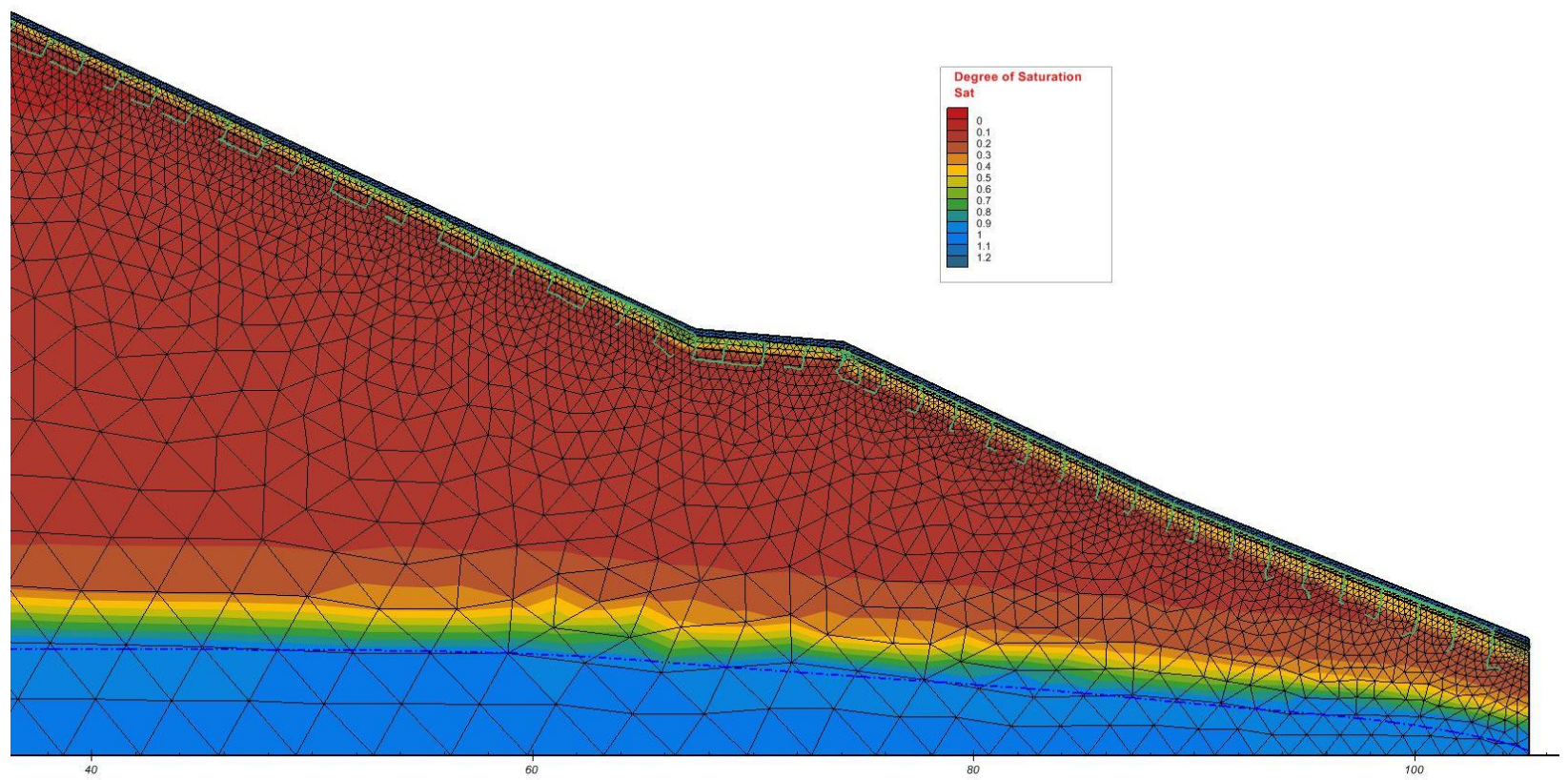

Figure 16. Day 3-Conventional Planar Slope (Ditch G) saturation with streamlines 


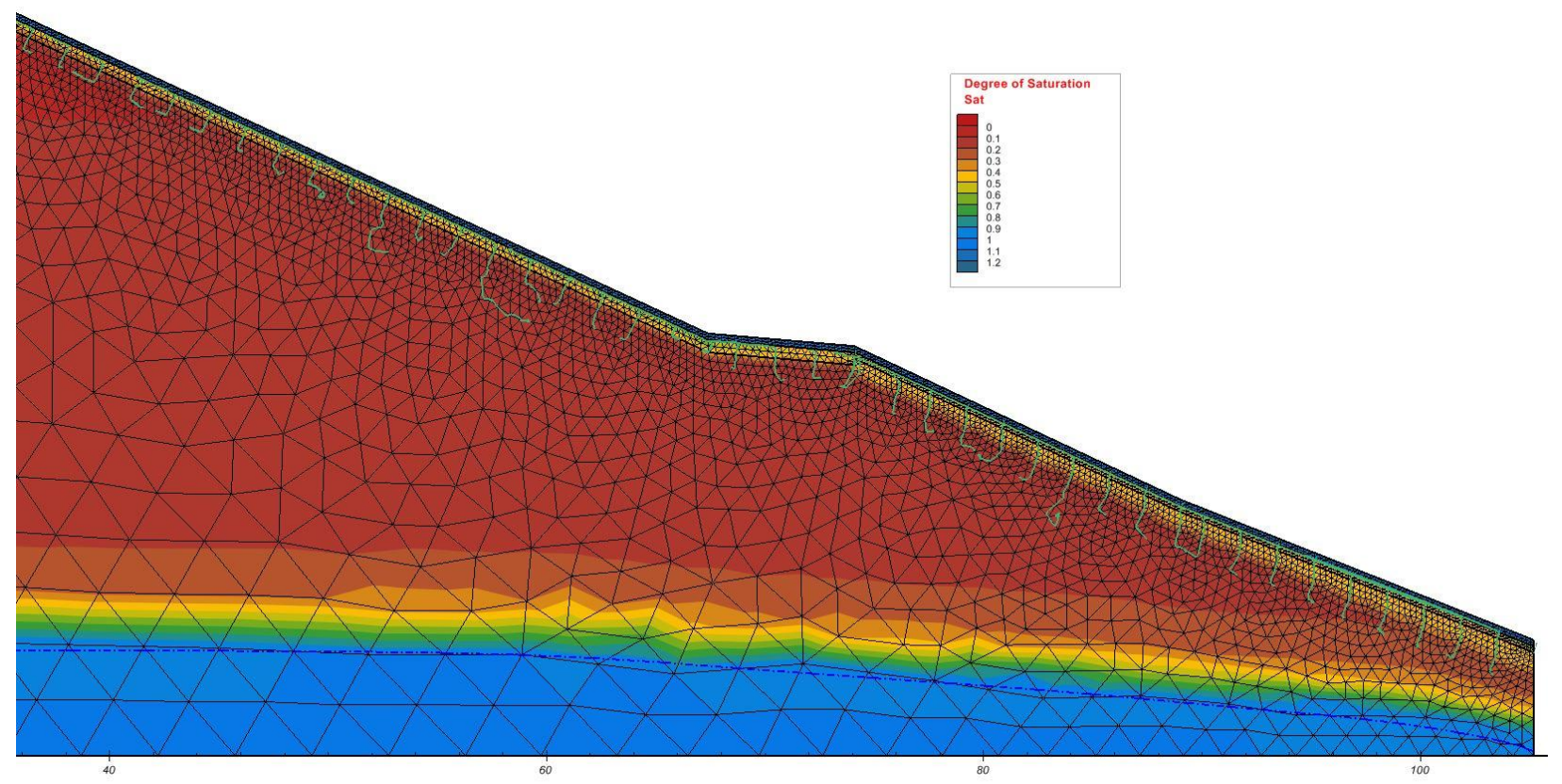

Figure 17. Day 4-Conventional Planar Slope (Ditch G) saturation with streamlines

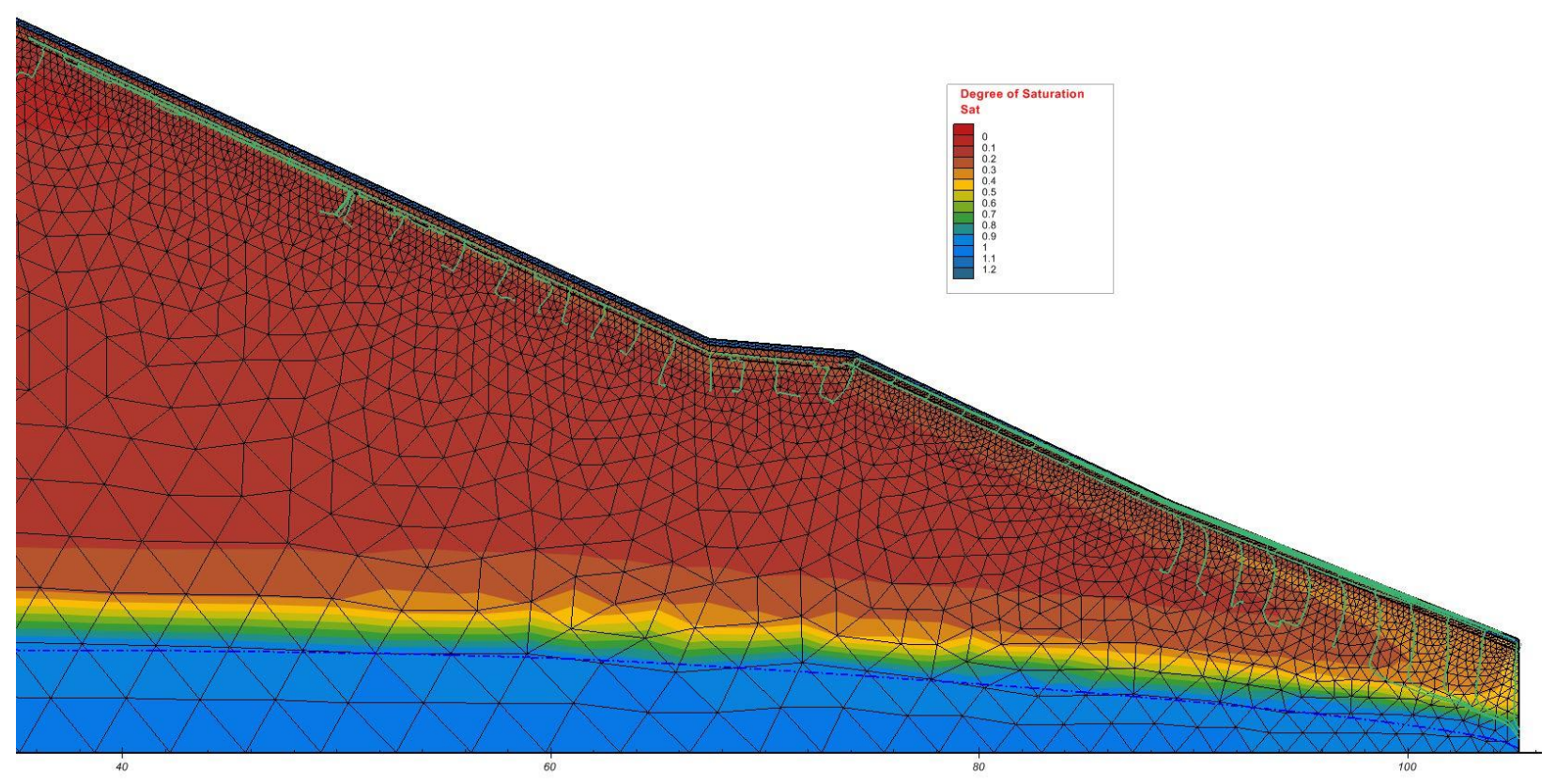

Figure 18. Day 15-Conventional Planar Slope (Ditch G) saturation with streamlines 


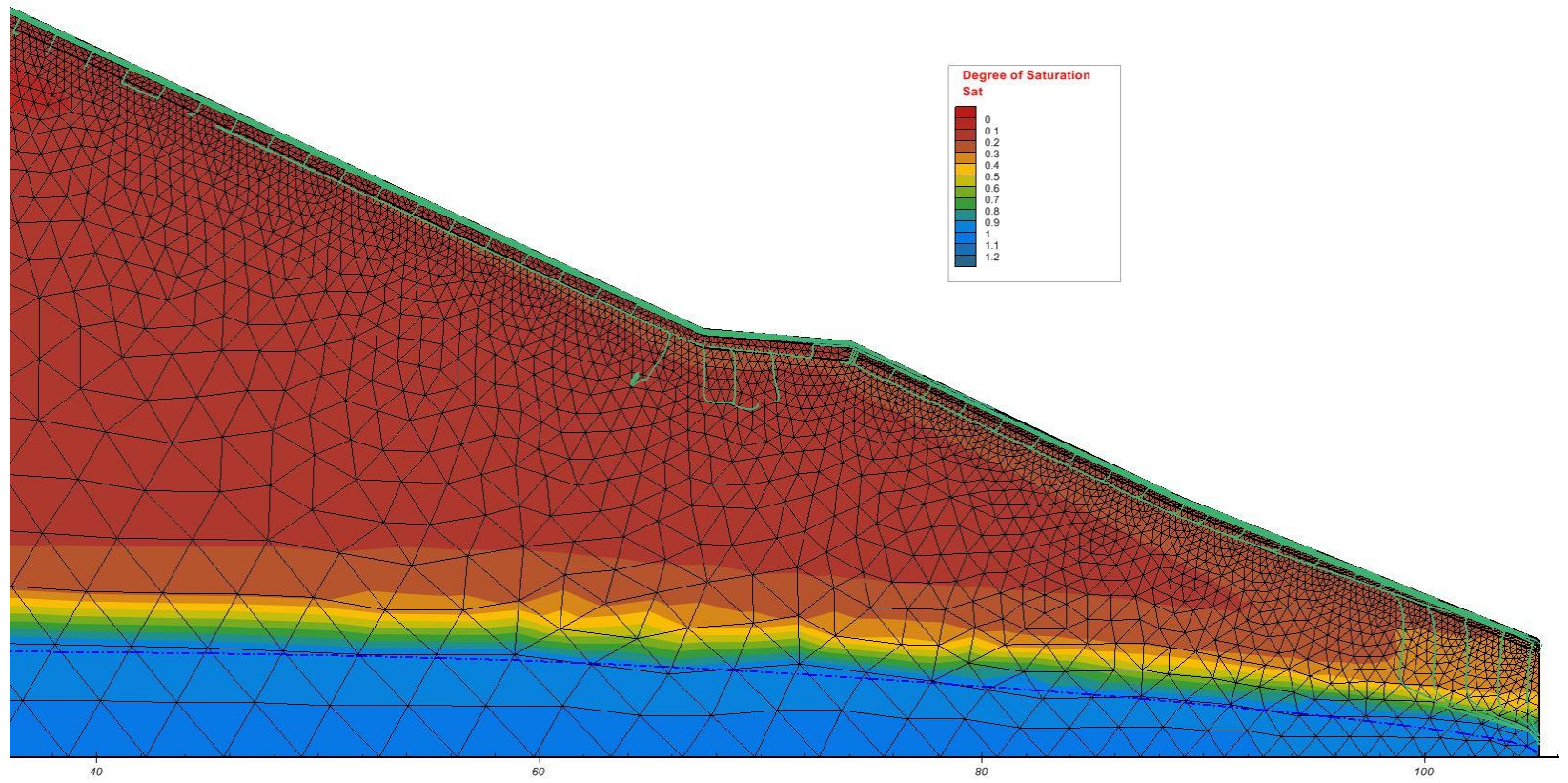

Figure 19. Day 25-Conventional Planar Slope (Ditch G) saturation with streamlines

On day 3 the growth layer is at $100 \%$ saturation, while the growth layer is at 40 to 50 percent saturation 48 hours after the storm has occurred. Saturation is starting to build up at the toe of slope, which is an indication of pore-pressure build-up. Streamlines are able to form due to $50 \%$ saturation in the barrier. Day 4 is similar in saturation with the growth layer still completely saturated and the streamlines are starting to get larger as the saturation in the barrier increases. The streamlines are gaining magnitude at the downslope toward the toe. On day 20, the growth layer is still completely saturated, but the hydraulic barrier has decreased back to $\mathrm{S}=20$ to $30 \%$. There is still more saturation at the toe of the slope which is expected since the toe is closer to the phreatic surface. The streamlines can only be seen near the toe of the slope and the downslope to the bench. On the last day (day 25), the growth layer remains completely saturated, but the hydraulic barrier has almost completely desaturated. The desaturating of the barrier as time passes causes more water to pass from the barrier into the fill. The saturation in the barrier is only 15 to $20 \%$ saturation, and the streamlines only exist at the bench and toe of the planar slope. The conventional planar slope also has no issues with mesh generation issues within the model.

\section{Geomorphic Slope (GLD-C) Saturation and Streamlines}

Figures 20 to 23 show the saturation of the geomorphic slope before and after the storm event. Table 22 shows helps to identify the saturation on each corresponding day. 
Table 22. Saturation of growth layer and hydraulic barrier

\begin{tabular}{|c|c|c|}
\hline \multicolumn{3}{|c|}{ Geomorphic Channel-C } \\
\hline Day & Growth Layer Saturation (\%) & Hydraulic Barrier Saturation (\%) \\
\hline 3 & 100 & 50 \\
\hline 4 & 100 & 60 \\
\hline 15 & 100 & 30 to 35 \\
\hline 25 & 100 & 20 to 25 \\
\hline
\end{tabular}

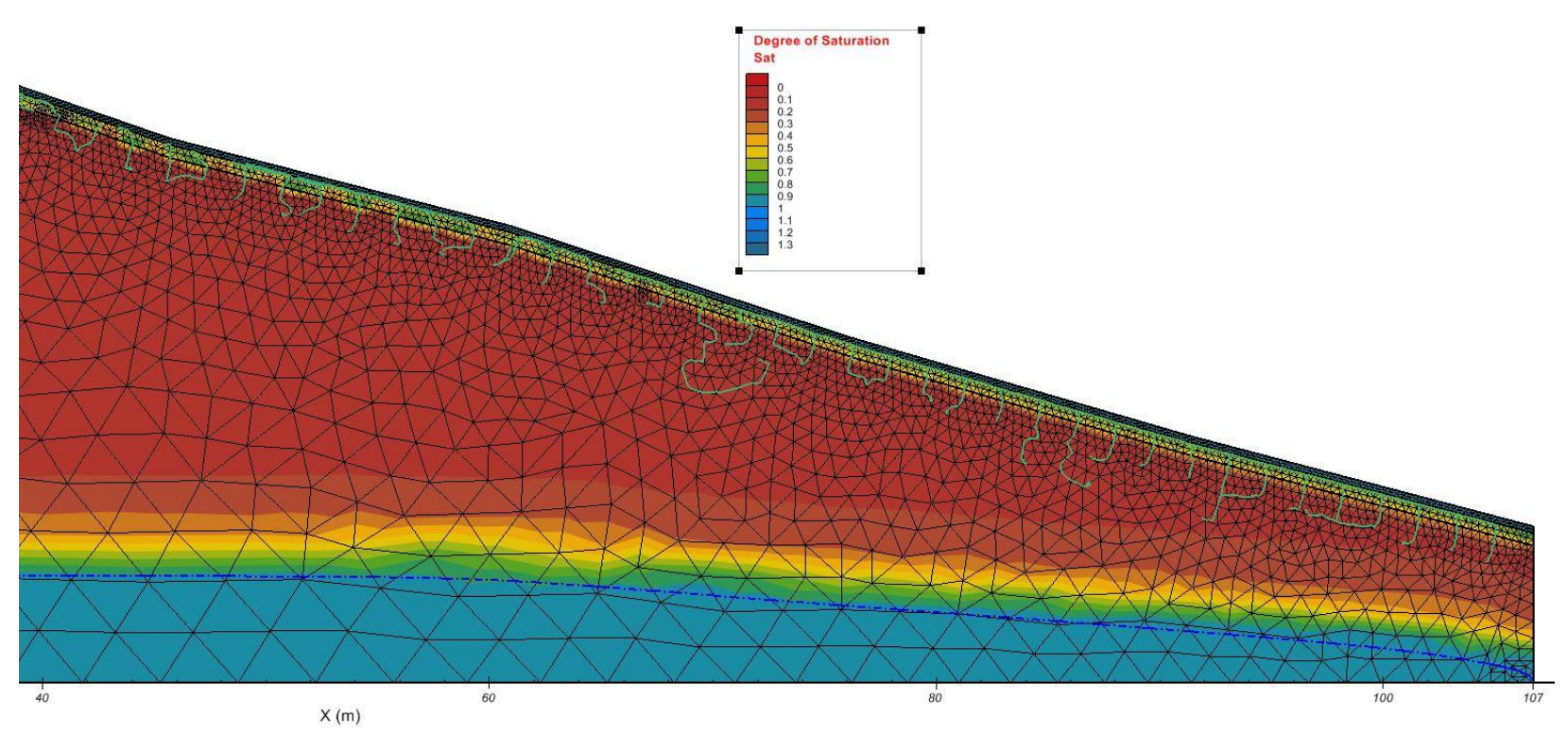

Figure 20. Day 3-Geomorphic Slope (GLD-C) saturation with streamlines 


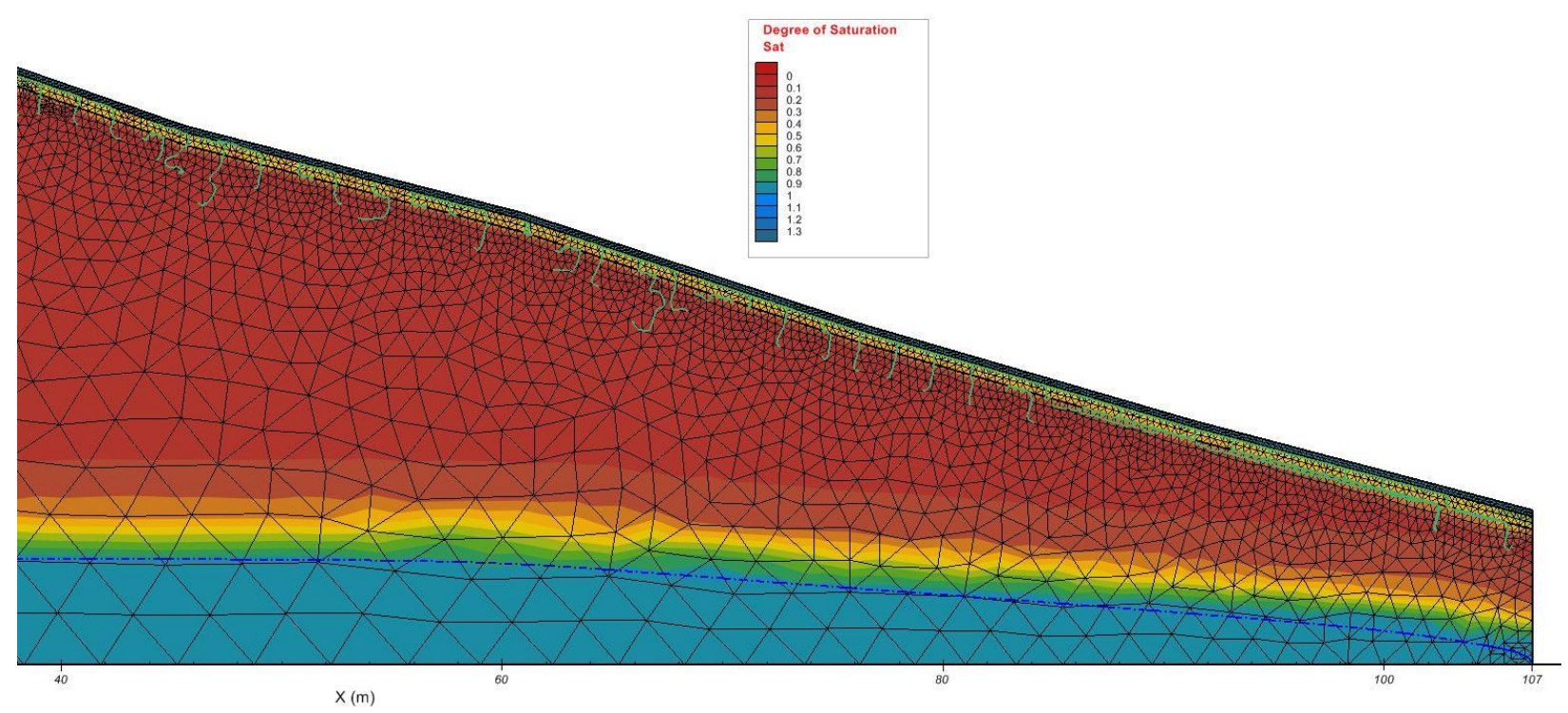

Figure 21. Day 4-Geomorphic Slope (GLD-C) saturation with streamlines

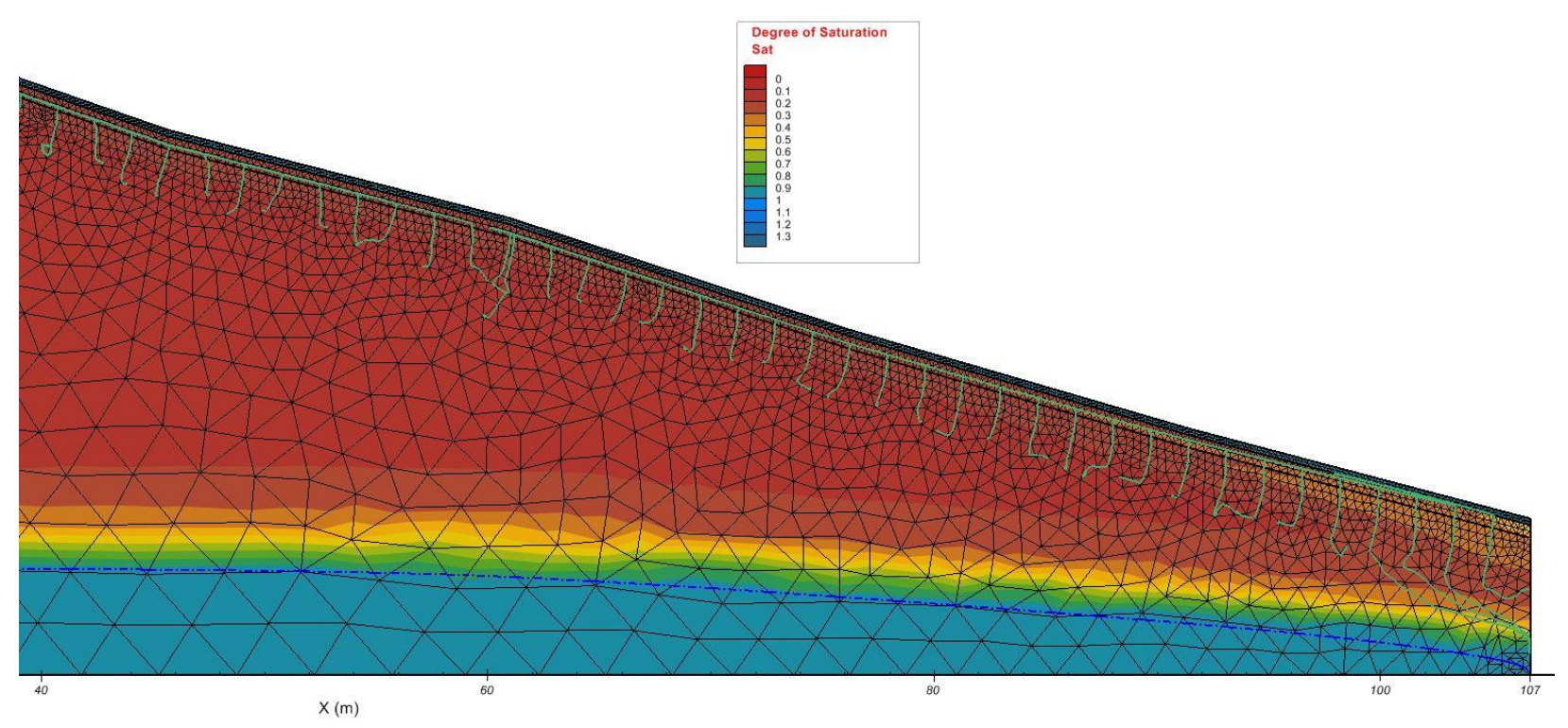

Figure 22. Day 15-Geomorphic Slope $(G L D-C)$ saturation with streamlines 


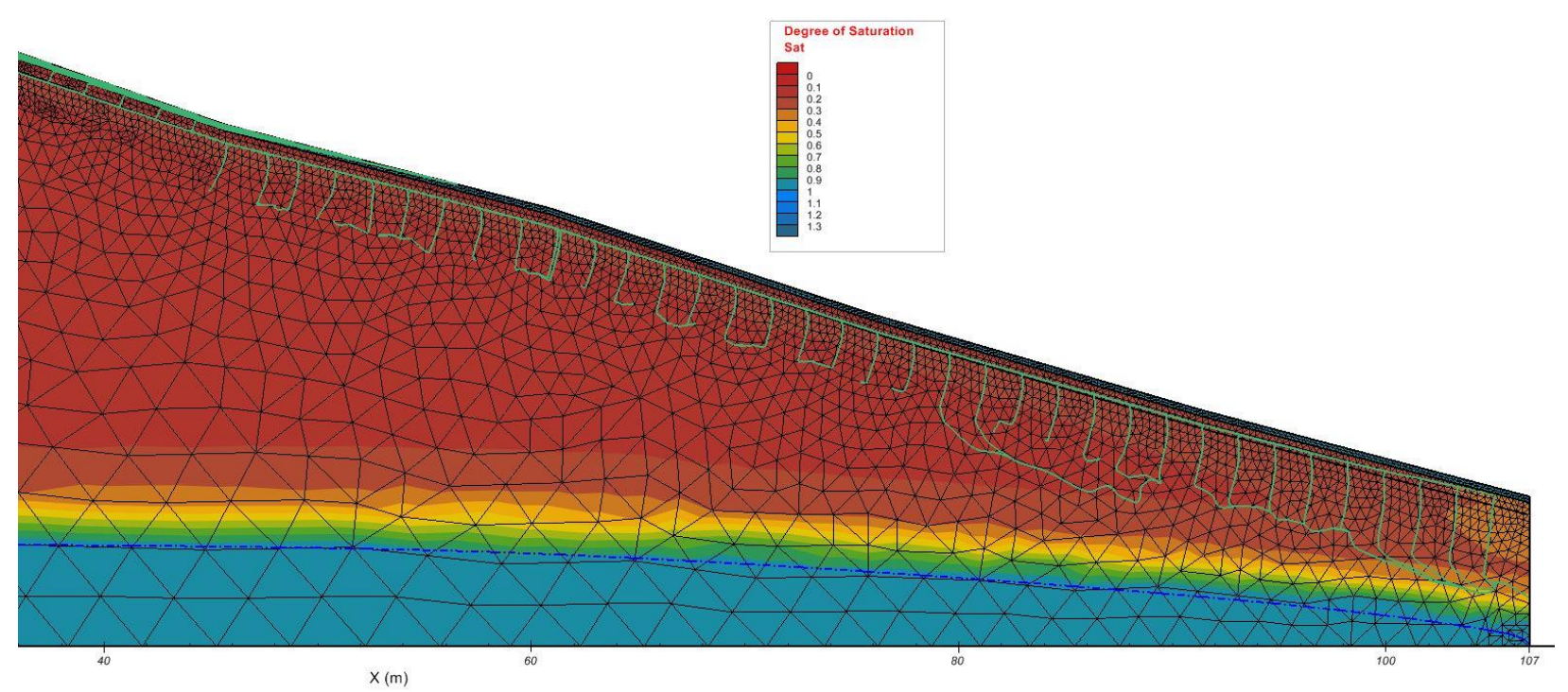

Figure 23. Day 25-Geomorphic Slope (GLD-C) saturation with streamlines

On day 3, 48 hours after the storm occurrence; the growth layer has reach $100 \%$ saturation, and the hydraulic barrier is at $\mathrm{S}=50 \%$ similar to the conventional planar slope. There is no evidence of increased saturation at the toe of the slope. Streamlines are starting to generate with saturation at $50 \%$ in the barrier. Day 4 shows that the growth layer remains fully saturated and the hydraulic barrier has reached $60 \%$ saturation. There is still no change of saturation at the toe of the slope indicating a pore-pressure build-up that was evident in the conventional planar slope saturation. The day 4 streamlines are more prevalent up the slope than at the toe. As time continues to Day 15, the hydraulic barrier has desaturated to 30 to $35 \%$ saturation. The growth layer remains at $100 \%$ saturation. The toe of the slope is starting to have increased saturation, which indicates a build-up in pore pressure. The streamlines on Day 15 are also much more prevalent as desaturation occurs, which is expected. The last day (Day 25), shows that the growth layer remained fully saturated throughout the model. The growth layer staying fully saturated throughout 25 days is a sign that growth is capable, and a root matrix can form. Saturation in the hydraulic barrier has decreased to 20 to $25 \%$, and the streamlines are only forming on the downward 2/3rd's of the slope profile, meaning the water is draining down the slope and ponding is not occurring.

\section{Seepage/Stability Analysis}

As mentioned previously, after the seepage was simulated, it was then coupled with a slope stability analysis according to General Limit Equilibrium (GLE). By doing the seepage coupled with stability, a worst-case factor of safety could be attained. A flux line was inserted on both conventional planar and geomorphic profiles to track infiltration from the hydraulic barrier into the fill material. For the conventional planar slope, the flux line was inserted at the bench (67.4, $19.2 \mathrm{~m}$ ) and was ended at the toe of the slope $(105.2,4.4 \mathrm{~m})$. For the geomorphic slope the flux was line was inserted at the lower $2 / 3$ rd's of the profile $(45.7,24.5 \mathrm{~m})$ and was also drawn to the 
toe of the slope $(106.7,5.1 \mathrm{~m})$. The flux lines were inserted at these two points where large amounts of seepage occur according to the saturation and streamline figures (Figures 16-23). Table 23 and 24 shows the quantitative results for the precipitation/infiltration, and its corresponding factor of safety for the conventional planar and geomorphic slopes. The infiltration rates are for the cumulative model duration. The tables also show quantitative results done by another researcher doing a similar study on the same slope profiles (Stevens, 2016). Figures 24 and 25 shows where the critical failure occurs and its corresponding mean factor of safety.

Table 23. Quantitative seepage/stability analysis for conventional planar slope (Ditch G)

\begin{tabular}{|c|c|c|c|c|c|c|}
\hline \multicolumn{7}{|c|}{ Conventional Planar Slope (Ditch G) } \\
\hline $\begin{array}{c}\text { Growth } \\
\text { Layer }\end{array}$ & $\begin{array}{c}\text { Hydraulic Barrier } \\
\text { Thickness }\end{array}$ & $\begin{array}{c}\text { Volume } \\
\text { Precipitation }\end{array}$ & $\begin{array}{c}\text { Infiltration } \\
\text { Stability }\end{array}$ & $\begin{array}{c}\text { Mean } \\
\text { Stability }\end{array}$ & $\begin{array}{c}\text { HCV } \\
\text { Stability }\end{array}$ \\
\hline$\%$ by volume & meters (feet) & $\mathrm{m}^{3}$ & $\mathrm{~m}^{3}$ & FS & FS & FS \\
\hline $80 / 20$ & $0.6(2)$ & 15.59 & 2.66 & 1.53 & 1.64 & 1.76 \\
\hline $60 / 40$ & $0.6(2)$ (Stevens, 2016) & 18.11 & 8.25 & N/A & 1.30 & N/A \\
\hline
\end{tabular}

Table 24. Quantitative seepage/stability analysis for geomorphic slope (GLD-C)

\begin{tabular}{|c|c|c|c|c|c|c|}
\hline \multicolumn{7}{|c|}{ Geomorphic Slope (GLD-C) } \\
\hline $\begin{array}{c}\text { Growth } \\
\text { Layer }\end{array}$ & $\begin{array}{c}\text { Hydraulic Barrier } \\
\text { Thickness }\end{array}$ & $\begin{array}{c}\text { Volume } \\
\text { Precipitation }\end{array}$ & Infiltration & $\begin{array}{c}\text { LCV } \\
\text { Stability }\end{array}$ & $\begin{array}{c}\text { Mean } \\
\text { Stability }\end{array}$ & $\begin{array}{c}\text { HCV } \\
\text { Stability }\end{array}$ \\
\hline$\%$ by volume & meters (feet) & $\mathrm{m}^{3}$ & $\mathrm{~m}^{3}$ & FS & FS & FS \\
\hline $80 / 20$ & $0.6(2)$ & 15.37 & 5.92 & 2.08 & 2.12 & 2.15 \\
\hline $60 / 40$ & $0.6(2)$ (Stevens, 2016) & 15.57 & 6.92 & N/A & 1.70 & N/A \\
\hline
\end{tabular}




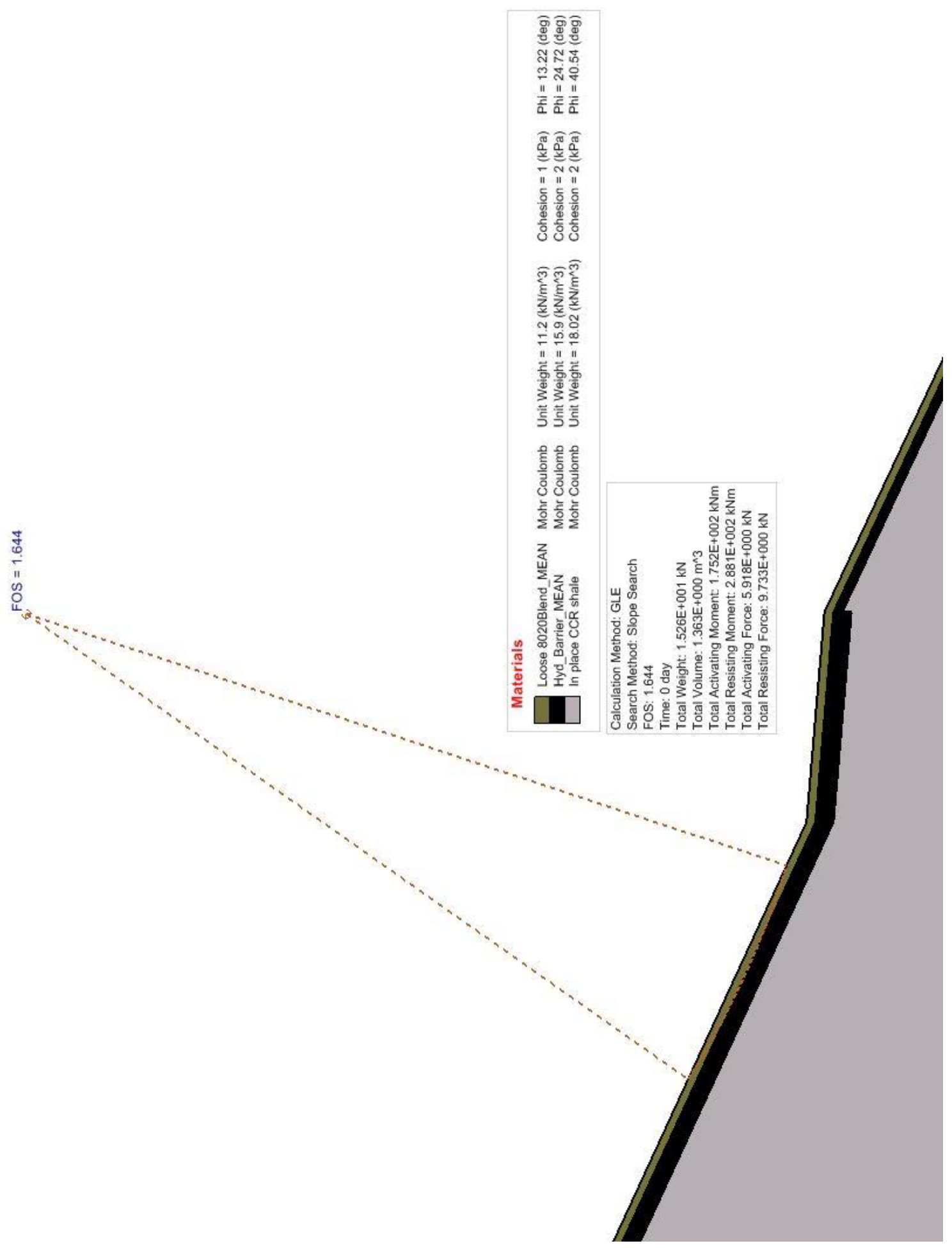

Figure 24. Mean factor of safety/critical area for conventional planar slope (Ditch G) 


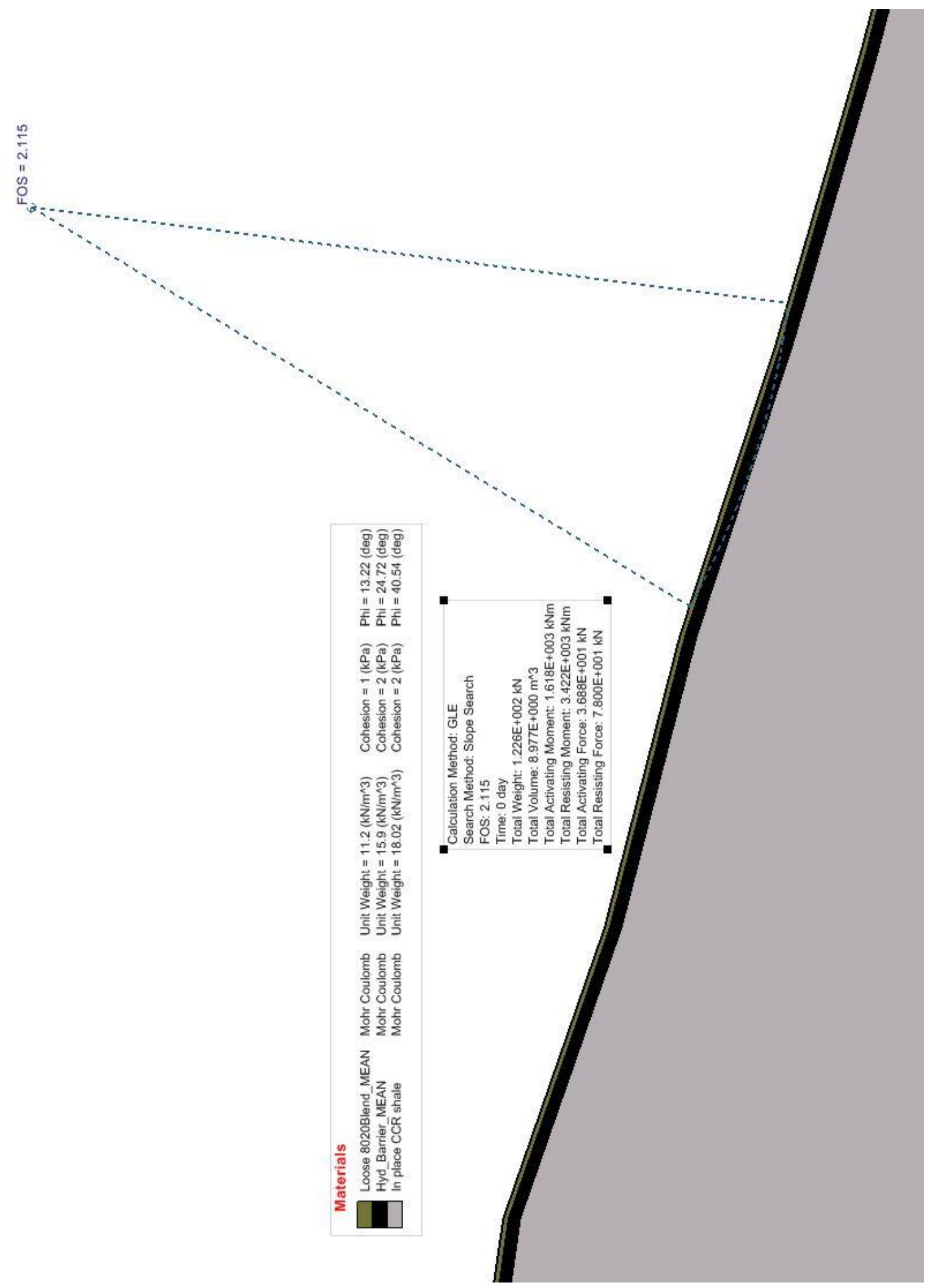

Figure 25. Mean factor of safety/critical area for geomorphic slope (GLD-C) 


\section{Conventional Planar Slope (Ditch G) Conclusions}

1. Table 23 shows that the model simulated by Stevens (2016) had $2.52 \mathrm{~m}^{3}$ more of precipitation than the model simulated for this research. This could be attributed to a different boundary condition for the 100-year storm.

2. A large decrease in infiltration is also noted between Stevens (2016) and the model simulated for this research. The model for this research had a $5.59 \mathrm{~m}^{3}$ decrease in infiltration. This is due to a 50\% reduction of $\mathrm{MGro}^{\mathrm{TM}}$ in an 80/20 growth layer compared to a 60/40 growth layer. The 80/20 layer allows less water to be retained in the $\mathrm{MGro}^{\mathrm{TM}}$, which could then leach into the barrier and fill material during desaturation.

3. The large reduction in infiltration also leads to an increased mean factor of safety (1.64). The 1.30 factor of safety is due to the large volume (8.25) of infiltration (Stevens. 2016).

4. The LCV factor of safety shows that even under lesser friction angle values, the slope remains stable with a $\mathrm{FS}=1.53$, which greater than $\mathrm{FS}=1.50$, which is recommended by Superfesky and Michael (2007).

5. Figure 24 shows that the critical area of failure for the mean factor of safety occurs directly upslope from the bench. The critical area shows that the failure only occurs on the 80/20 growth layer and does not reach the hydraulic barrier. The reason the failure occurs here is due to sloughing, which is the loss of cohesion due to high saturation. The growth layer remains $100 \%$ saturated throughout the 25 -day model.

6. Grass may be able to bind the structure together in a root matrix increasing the overall stability.

\section{Geomorphic Slope (GLD-C) Conclusions}

7. Table 24 shows that both studies had similar volumes of precipitation for the 100 -year storm.

8. The $80 / 20$ growth layer proved to decrease the infiltration by $1.00 \mathrm{~m}^{3}$ compared to $60 / 40$ Stevens (2016). The $50 \%$ reduction in $\mathrm{MGro}^{\mathrm{TM}}$ allows less water to reside in the growth layer, and increase runoff towards the toe for the entire site.

9. The geomorphic slope with the 80/20 layer had a much higher factor of safety compared to Stevens (2016). A 0.42 increase in factor of safety can be attributed to a more competent hydraulic barrier. The hydraulic barrier had a friction angle ranging from 24.12 to 25.08 degrees compared to Stevens (2016) 43.21 to 44.96 degrees (Table 14). The friction angles that range from 43.21 to 44.96 were done according to a direct shear test compared to an ICU test.

10. The geomorphic slope also proved to have a much higher factor of safety compared (2.12) to the conventional planar slope (1.64). The reason for a large increase in factor of safety is due to the steepness of the conventional planar slope compared to the geomorphic slope.

11. Figure 25 shows that the critical area occurs in the middle of the slope profile. The middle of the geomorphic slope is where infiltration is occurring always throughout the 
25-day model according to the streamlines in Figures 20 to 23. The critical area also breaks past the growth layer and into the hydraulic barrier, which is a major concern. The reason for failure to occur in the barrier is due to a large concentration of saturation greater than $50 \%$.

12. The terrain profile also plays a role in the failure reaching the hydraulic barrier. There is no bench to alleviate driving forces that as there is in the conventional planar profile.

13. As mentioned in the conventional planar slope, a root matrix will form in the growth layer and may increase the overall stability. This may help the geomorphic slope from the failure breaking into the hydraulic barrier that is seen in Figure 25. 


\section{Conclusions and Recommendations}

From the geotechnical investigation to the Finite Element Modeling, the conventional planar and geomorphic slope profiles show that the major areas of concern for this proposed cap and cover design lie in the overall physical properties of the CCR and 80/20 CCR/MGro ${ }^{\mathrm{TM}}$ growth layers. The hydraulic barrier shows that it performs as expected in the modeling being able to decrease infiltration compared to the 60/40 layers. The CCR material also proves to be more competent in the 24.12 to 25.08 degrees area compared to the high 43.21 to 44.96 degrees (Table 14). This was shown in the modeling, giving higher factors of safety under a worst-case scenario. Some recommendations that can be taken into consideration are as follows:

1. It is recommended that an isotropic consolidated drained (ICD) test be run on the $80 / 20$ and 60/40 growth layers as a check to see how much the friction angle would change between a ICU, ICD, and direct shear tests.

2. The geomorphic slope proves to be a more stable slope compared to conventional design. It has higher infiltration volumes for this research than the conventional planar slopes, but the factor of safety values show that it would be a more stable slope long term.

3. With higher infiltration values for the geomorphic slope, the failure was able to break into the hydraulic barrier. This was the case with the model without grass growing. With grass growing, a root matrix can form and bind the structure together making it more stable.

4. Grass growing, and the formation of a root matrix will also promote evapotranspiration for the entire site.

5. The $80 / 20$ growth layer shows the ability to decreases infiltration compared to the $60 / 40$ layer. The $50 \%$ reduction of $\mathrm{MGro}^{\mathrm{TM}}$ allows a lesser amount of water to reside in the growth layer and promote runoff towards the toe of the slope

6. Throughout the 25-day model of the conventional planar slope, large amounts of saturation were prevalent at the toe of the slope. This is expected, but could raise concern due to a slope blowout at the toe with increased pore-water pressure.

7. Implement rock drains at the toes of both slope profiles to reduce saturation/pore-water pressure build-up.

8. Complete more advanced modeling in seepage/infiltration of geomorphic and conventional planar slopes to see if there are any diminishing returns with either landform.

9. The $80 / 20$ growth layer proves to be a viable growth layer for the cap and cover design. The 50\% reduction of $\mathrm{MGro}^{\mathrm{TM}}$ compared to the $60 / 40$ growth layer could also greatly save costs in the construction of the structure. 


\section{References}

Albuquerque, A.J.J., 1994, Geoenvironmental Aspects of Coal Refuse-Fly Ash Blends, M.S. Thesis, Virginia Polytechnic Institute and State University, Blacksburg, VA.

Almes, R.G. and A. Butail, 1976, "Coal Refuse: Its Behavior Related to the Design and Construction of Coal Refuse Disposal Facilities," Proceedings of the Seventh Ohio Valley Soils Seminar on Shales and Mine Wastes, Lexington, KY.

ASTM Designation D422. (2007). "Standard Test Method for Particle-Size Analysis of Soils." Annual Book of ASTM Standards, American Society of Testing Materials, Easton, MD.

ASTM Designation D698. (2007). "Standard Test Methods for Laboratory Compaction Characteristics of Soil Using Standard Effort (12400 ft-lbf/ft3 (600 KN-m/m3))." Annual Book of ASTM Standards, American Society of Testing Materials, Easton, MD.

ASTM Designation D5084. (2010). "Standard Test Methods for Measurement of Hydraulic Conductivity of Saturated Porous Materials Using a Flexible Wall Permeameter.” Annual Book of ASTM Standards, American Society of Testing Materials, Easton, MD.

ASTM Designation D4767. (2011). "Standard Test Method for Consolidated Undrained Triaxial Compression Test for Cohesive Soils." Annual Book of ASTM Standards, American Society of Testing Materials, Easton, MD.

Carpenter, A. F., \& Fernandez, I. J. (2000). "Pulp sludge as a component in manufactured topsoil”. Journal of Environmental Quality, 29(2), 387-397.

Daniels, W.L., Haering, K., Evanylo, G., Burger J., \& Beck, M. (2013). “Suitability of MeadWestVaco residuals for utilization as soil amendments on reclaimed mined lands and native soils" Final Report Virginia Tech Department of Crop \& Soil Environmental Sciences

D’Appolonia Consulting Engineers Inc, 2009. Engineering and Design Manual Coal Refuse Disposal Facilities, second ed. U.S. Department of Labor, Mine Safety and Health Administration [MSHA].

Department of the Army, U.S. Army Corps of Engineers (2003). Engineering and Design, "Slope Stability" Manual No. 1110-2-1902.

DePriest, Nathan C. (2015). “Assessing the conceptual design, groundwater movement, and contaminant desorption of geomorphic landform design as an alternative for conventional valley fill surface mine reclamation.” Doctoral Dissertation, West Virginia University Morgantown, WV 
DePriest, N.C., Hopkinson, L.C., Quaranta, J.D., and Ziemkiewicz, P.F. (2015). “Geomorphic landform design alternatives for an existing valley fill in central Appalachia, USA: Quantifying the key issues.” Ecological Engineering, 81, 19-29.

Duncan, J. M. (2000). "Factors of safety and reliability in geotechnical engineering." Journal of Geotechnical and Geoenvironmental Engineering, 126(4), 307-316.

Hegazy, Y. A., Cushing, A. G., \& Lewis, C. J. (2004). Physical, Mechanical and Hydraulic Properties of Coal Refuse for Slurry Impoundment Design. D'Appolonia Engineering, Monroeville, PA.

Koloski, J.W., Schwarz, S.D., Tubbs, D.W., Geotechnical Properties of Geologic Materials, Engineering Geology in Washington, Volume 1, Washington Division of Geology and Earth Resources Bulletin, 78, 1989.

Laubenstein, J. (2004). "Beneficial use of short paper fiber (paper mill sludge) for pollution prevention in the mining industry." TAPPI Paper Summit-Spring Technical and International Environmental Conference.

Lorimer, J.T. (2016). “Geomorphic Landform Design Principles Applied to an Abandoned Coarse Coal Refuse Pile on Steep Terrain in Central Appalachia”. M.S. Thesis, West Virginia University, Morgantown, WV.

Lu, Ning, and William J. Likos. Unsaturated Soil Mechanics. Hoboken, NJ: Wiley, 2004. Print.

McCutcheon, H.P., 1983, Liquefaction and Cyclic Mobility of Coal Refuse Material, M.S. Thesis, Carnegie Mellon University, Pittsburgh, PA.

Nicolau, J.M. (2003). "Trends in relief design and construction in opencast mining reclamation." Land Degradation and Development, 14, 215-226. DOI: 10.1002/ldr.54

Russell, H., DePriest, N., and Quaranta, J.D. (2014). “Stability analysis comparison of conventional valley-fill to geomorphic landform designs." Trans., Society of Mining Metallurgy and Exploration, 336, 414-420.

Saxena, S.K., D.E. Lourie and J.S. Rao, 1984, "Compaction Criteria for Eastern Coal Waste Embankments," Journal of the Geotechnical Engineering Division, ASCE, Vol. 110, No. GT2, pp. 262-284.

Schor, H.J., and Gray, D.H. (2007). Landforming: an environmental approach to hillside development, mine reclamation and watershed restoration, John Wiley \& Sons, Hoboken, NJ. 
Stevens, J.R., (2016). "Geotechnical testing and Finite Element Modeling of Geomorphic Landform Design with a Multi-Layer Cap and Cover System". West Virginia University, Morgantown, West Virginia, USA.

Superfesky, M., Michael P. (2007). "Excess Spoil Minimization and Fill Stability.” Proc., SME Annual Meeting, SME, Denver, CO, 1-13.

Torres, G.H. (2011). "Estimating the soil-water characteristic curve using grain-size analysis and plasticity index." M.S. Thesis, Arizona State University, Tempe, AZ

Toy, T.J., and Chuse, W.R. (2005). "Topographical reconstruction: a geomorphic approach.” Ecological Engineering, 24, 29-35.

Ward, Ken Jr. (2001, August 12). “A toxic legacy.” Charleston Gazette-Mail. Retrieved from: http://www.wvgazettemail.com/article/20010812/ARTICLE/308129998/ 